\title{
NANOTECHNOLOGY AND THE NEED FOR RISK GOVERNANCE
}

Ortwin Renn, Department of Environmental Sociology, University of Stuttgart, Germany; and

Mihail.C. Roco, National Science Foundation, 4201 Wilson Blvd., Suite 505, Arlington, VA 22230, USA, mroco@nsf.gov

November 10, 2005

\section{Abstract}

After identifying the main characteristics and prospects of nanotechnology as an emerging technology, the paper presents the general risks associated with nanotechnology applications and the deficits of the risk governance process today, concluding with recommendations to governments, industry and other stakeholders. The International Risk Governance Council (IRGC) has identified a governance gap between the requirements pertaining to the nano- rather than the micro-/macro- technologies. The novel attributes of nanotechnology demand different routes for risk-benefit assessment and risk management, and at present, nanotechnology innovation proceeds ahead of the policy and regulatory environment. In the shorter term, the governance gap is significant for those passive nanostructures that are currently in production and have high exposure rates; and is especially significant for the several 'active' nanoscale structures and nanosystems that we can expect to be on the market in the near future. Active nanoscale structures and nanosystems have the potential to affect not only human health and the environment but also aspects of social lifestyle, human identity and cultural values. The main recommendations of the report deal with selected higher risk nanotechnology applications, shortand long-term issues, and global models for nanotechnology governance.

Keywords: nanoscience, nanoengineering, global risk governance, risk communication, risk management, scenarios for nanotechnology development

\section{BACKGROUND}

\section{Defining Nanotechnology}

Nanotechnology is still in an early phase of development, and is sometimes compared in the literature to information technology in the 1960's and biotechnology in the 1980's. Nanotechnology refers to the development and application of materials, devices and systems with fundamentally new properties and functions because of their structures in the range of about 1 to 100 nanometres (Siegel et al., 1999). It involves the manipulation and/or creation of material structures at the nanoscale, in the atomic, molecular and supramolecular realm. At the nanoscale, the characteristics of matter can be significantly changed, particularly under $10-20 \mathrm{~nm}$, because of properties such as the dominance of quantum effects, confinement effects, molecular recognition, and an increase in relative surface area. Downsized material structures of the same chemical elements change their mechanical, optical, magnetic and electronic properties, as well as chemical reactivity leading to surprising and unpredicted, or unpredictable, effects. In essence, nanodevices exist in a unique realm, where the properties of matter are governed by a complex combination of classic physics and quantum mechanics. At the nanometre scale manufacturing capabilities (including by self assembly, templating, stamping, and fragmentation) are broad and can lead to numerous efficient outcomes.

Nanoscience is the result of interdisciplinary cooperation between physics, chemistry, biotechnology, material sciences and engineering toward studying assemblies of atoms and molecules. More than in other domains, nanotechnology requires the integration of many scientific, engineering and technical disciplines and competences. Applications of nanotechnology will penetrate nearly all sectors and spheres of life (communication, health, labour, mobility, housing, relaxation, energy, food) and will be accompanied by changes in the social, economic, ethical and ecological spheres.

As with other new technologies, nanotechnology evokes enthusiasm and high expectations: for new progress in science and technology, new productive applications and economic potential on the one 
hand; and for concerns about risks and unforeseen side effects on the other (Roco and Bainbridge, 2001 and 2005; Roco and Tomellini, 2002). At this point in time, the assessment of the social, juridical and ethical consequences of nanotechnology relies more on hypothetical or even speculative assumptions than on rigorous scientific analysis (Hanssen and van Est, 2004). Various science fiction scenarios and literary narratives have picked up nanotechnology as a major theme of their projections for the future.

\section{The Promise of Nanotechnology}

The Research and Development (R\&D) areas of focus are shifting progressively from passive nanostructures to nanosystems as suggested in Figure 1 (Roco, 2005a). In 2000, the US National Science Foundation (NSF) estimated that $\$ 1$ trillion worth of products worldwide would incorporate nanotechnology in key functional components by the year 2015 (Roco and Bainbridge, 2001). The corresponding industries will require about 2 million workers in nanotechnology, and about three times as many jobs in supporting activities. These estimates were based on a broad industry survey and analysis in the Americas, Europe, Asia and Australia, and continue to hold in 2005.

Nanotechnology promises to be one of the defining technologies of the $21^{\text {st }}$ century. Based on the ability to measure, manipulate and organise material on the nanoscale - it is set to have significant implications (Roco and Bainbridge, 2001 and 2005). Envisaged breakthroughs for nanotechnology include order-of-magnitude increases in computer efficiency, advanced pharmaceuticals, biocompatible materials, nerve and tissue repair, surface coatings, catalysts, sensors, telecommunications and pollution control. This potential has encouraged a dramatic rise in $R \& D$ expenditure and all developed countries and many countries in development have begun to invest in nanotechnology. Government investments in each of the US, Japan, EU and the "Rest of the world" (including Canada, China, Australia, Korea, Taiwan, and Singapore) reached about $\$ 1$ billion for R\&D in 2005, with the fastest growing being the "Rest of the world". The US National Nanotechnology Initiative (NNI) announced in 2000 has been followed by nanotechnology R\&D programmes in about 60 countries within five years. In 2005, the US Government spent $\$ 1081$ million through its National Nanotechnology Initiative, Japan about $\$ 950$ million, whilst the European Commission has allocated $\$ 1.3$ billion under its multi-annual Sixth Framework Programme (DTI, 2002). Corresponding R\&D investments for nanotechnology by industry worldwide are at about the same level, but with a higher rate of yearly increase as compared to government investments.

Figure 1. Timeline for beginning of industrial prototyping and nanotechnology commercialisation: Four overlapping generations of products and processes

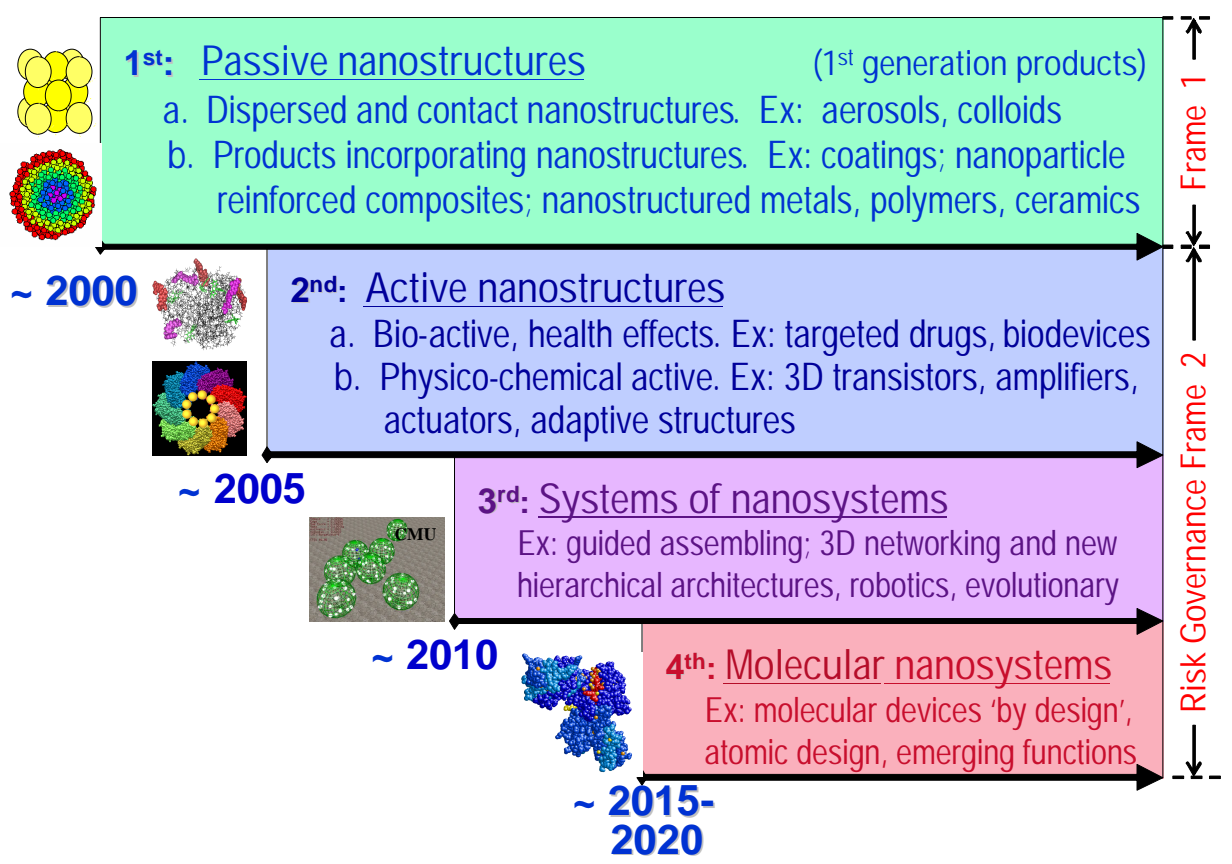


Significant applications of nanosciences and nanoengineering lie in the fields of, inter alia, medicine, pharmaceutics, cosmetics (such as sun creams), biotechnology, processed food, chemical engineering, high performance materials, electronics, information technologies, precision mechanics, optics, analytics, energy production and environmental sciences (Jopp 2003). A range of projected beneficial applications are also related to nanotechnology, for example, the conservation of resources and the diminishment of pollution. Thousands of new patents are being announced in this area each year (Huang et al, 2004). Titanium dioxide, carbon black, zinc oxide and iron oxide make up the majority of the nanoparticles in industry, however, there are dozens of other nanostructures and particles at the research stage that could enter the manufacturing world soon as part of the first generation of nanoproducts (see evolution of nanotechnology in Figure 1). The Small Times survey, using the $\mathrm{NNI}$ definition of nanotechnology, has identified over 700 products incorporating nanotechnology in the US alone (Small Times, 2005).

\section{What is Special about Nanotechnology as an Emerging Field?}

Nanotechnology has many characteristics which both increase its potential and provide new issues for global risk governance. Also, the implications of nanotechnology are broad because its applications are at the confluence with modern biology, digital revolution and cognitive sciences (nano-bio-infocogno converging technologies or NBIC in Roco and Bainbridge 2003), and many long-term outcomes are the result of NBIC integration.

Most importantly, nanotechnology:

- Offers a broad technology platform (for industry, biomedicine, environment and an almost indefinite array of potential applications).

- Reaches the basic level of organisation of atoms and molecules, where the fundamental properties and functions of all manmade and living systems are defined.

- Reverses the trend of specialisation of scientific disciplines, providing unifying concepts for research and education, and leading to system integration in engineering and technology.

- Has stimulated all developed countries and many countries in development to invest in nanotechnology (over 60 countries since 2000, R\&D investment exceeds $\$ 8 B$ in 2005).

- Has broadened and changed manufacturing capabilities (including by selfassembling, templating, stamping, fragmentation, etc.) with the promise of more efficient outcomes.

- Has influenced the speed and scope of R\&D that exceeds for now the capacity of regulators to assess human and environmental impact.

o Has become one of the main drivers for technological/economic change and industrial competition.

In response to these specific characteristics of nanotechnology, the national $R \& D$ programmes established in the last five years are highly integrative and involve multiple funding agencies. For illustration, the initial strategy of the National Nanotechnology Initiative in the US in 2000 was based on long-term planning, inclusiveness of potential contributors, the establishment of multidisciplinary partnerships amongst government, industry and international organisations, and the support of societal dimension studies from the beginning (Roco, 2004a).

\section{Four Generations of Nanotechnology Products and Processes}

Four overlapping generations of new nanotechnology products and processes (called below "nanoproducts") have been identified which have the potential for development in the interval 20002020: passive nanostructures, active nanostructures, systems of nanosystems, and heterogeneous molecular nanosystems (Figure 1: Roco 2004b). Each generation of products is marked by the creation of commercial prototypes using systematic control of the respective phenomena and manufacturing processing. Products may have components corresponding to different generations. The rudimentary capabilities of nanotechnology today for systematic control and manufacture at the nanoscale are expected to evolve significantly in complexity and degree of integration by 2020 .

- First generation of products, mainly after 2000- : passive (steady function) nanostructures include nanostructured coatings, dispersion of nanoparticles, surface nanopatterning, ultraprecision engineering, and bulk materials (nanostructured metals, polymers and ceramics). These nanostructured materials have steady or quasi-steady structures and functions (such as mechanical behaviour and chemical reactivity) during their use. The primary outcomes are components (such as particles, wires, nanotubes, etc.) with improved properties and functions because of their nanostructure. One may identify two subcategories: (a) dispersed and contact 
surface nanostructures such as nanoscale colloids (including cosmetics), aerosols and powders that may have significant exposure to biosystems; and (b) products incorporating nanostructures such as nanoscale layers in transistors or bulk materials. In nanomedicine, one would include joint replacement with biocompatible nanostructured materials and non-invasive and invasive diagnostics with nanoparticles and quantum dots for rapid patient monitoring. In nanoelectronics, one would include the scaling down "masked-lithography of thin-films" approach with simple nanoscale components (for example, nanolayers). Potentially high risk products include nanoparticles in cosmetics or food, which have high scale production and increased exposure rates. Other examples are ultrafine powders with fire and explosion hazards.

o Second generation of products, 2005 - : active (evolving function) nanostructures, for example, new transistors, amplifiers, targeted drugs and chemicals, actuators, molecular machines, light-driven molecular motors, plasmonics, nanoscale fluidics, laser-emitting devices, and adaptive structures. An 'active' nanostructure changes its state in time during its operation, for illustration, an actuator changes its dimensions, and a drug delivery particle changes its morphology and chemical composition. The new state may also be subject to other successive changes in the mechanical, electronic, magnetic, photonic, biological properties and other effects. One may identify two subcategories: (a) bioactive nanostructures with potential effects on human health and ecosystems; and (b) physico-chemical active nanostructures. Typical active nanostructures are components in nanoelectromechanical systems (NEMS), nanobiodevices, energy storage devices, and sensors which change their state during measurement. In nanomedicine, one would include cognitive capacity-assisting and enhancing devices, targeted cancer therapies, sensors for in vivo monitoring, localised drug delivery, neural stimulation and cardiac therapies. In nanoelectronics, one would include "directed self-assembly" structures leading to Complementary Metal-Oxide Semiconductors (CMOS) scaled to its ultimate limits (5-10 $\mathrm{nm}$ ) and the possible "post-CMOS" (but still "electron charge-based") integrating nanocomponents and nanodevices such as carbon-nanotube and single-electron "transistors". Examples of potentially high-risk products are: nano-bio interface devices, neuro-prosthesis, reactive devices placed in the environment, active devices in the human body, and devices for surveillance. Several potentially higher risk areas are: nano-biotechnology, neuro-electronic interfaces, nanoelectromechanical systems, agriculture and food systems and hybrid nanomanufacturing.

o Third Generation, 2010 - : system of nanosystems, use various syntheses and assembling techniques such as bio-assembling; networking at the nanoscale and multiscale and hierarchical architectures, robotics on surfaces, modular nanosystems, chemo-mechanical processing of molecular assemblies, and quantum-based nanoscale systems. In nanomedicine, one would include artificial organs built from the nanoscale, improved cell-material interactions for cell conditioning, and scaffolds for tissue engineering. In nanoelectronics, one would include possible new devices based on state variables other than electric charge (e.g., electron-spin, nuclear-spin or photonic states). Potential high risk products include: emerging behaviour robotics, evolutionary artificial organs, modified viruses and bacteria, and brain modification. Several potentially higher risk areas are: nanorobotics, regenerative medicine, brain-machine interface, nanoengineering in agriculture, nanosystems used for manufacturing and product processing, and other converging technologies applications.

o Fourth generation, 2015/2020 - : involves heterogeneous molecular nanosystems, where each molecule in the nanosystem has a specific structure and plays a different role. Molecules will be used as devices and fundamentally new functions will emerge from their engineered structures and architectures. This is approaching the way biological systems work, but in comparison biological systems are water-based, process the information relatively slowly, and have multiple hierarchical scales. Designing new atomic and molecular assemblies is expected to increase in importance, including macromolecules "by design" to self-assemble on multiple scales, nanoscale machines, subcellular interventions, directed and multiscale self-assembling, controlled interaction between light and matter with relevance to energy conversion, and exploiting quantum control. Nano-bio-info and cognitive sciences convergence will play an increased role in this generation. In nanomedicine, one would include nanoscale genetic therapies, cell ageing therapies, and nanoscale controlled stem cell therapies. In nanoelectronics, one would envision molecular and supramolecular components "by design" as modular components for transistors. Examples of potential high risk products are: molecular devices 'by design', molecules with atomic design, large nano-bio or hybrid systems with emerging functions, evolutionary cells and self-replication of large nanostructured systems. Several potentially higher risk areas are: neuromorphic engineering, 
complex systems, molecular nanosystems used for manufacturing and product processing, and human-machine interface.

\section{Governance and Risk Governance of Nanotechnology}

Governance includes the processes, conventions and institutions that determine:

$\ddot{y} \quad$ How power is exercised in view of managing resources and interests;

$\ddot{y} \quad$ How important decisions are made and conflicts resolved; and

$\ddot{y}$ How various stakeholders are accorded participation in these processes;

In the most common current usage of the term, "Governance" is seen as implying a move away from the previous government approach (a top-down legislative approach which attempts to regulate the behaviour of people and institutions in quite detailed and compartmentalised ways) to governance (which attempts to set the parameters of the system within which people and institutions behave so that self-regulation achieves the desired outcomes), or put more simply, the replacement of traditional "powers over" with contextual "powers to". In such a system, permeable and flexible system boundaries facilitate communication and support the achievement of higher level goals, while the government role will continue in this context. These assumptions underline the switch from government alone to governance in debates about the modernisation of policy systems implying a transition from constraining to enabling types of policy or regulation (i.e. from "sticks" to "carrots") (Lyall and Tait, 2005).

Risk governance includes the totality of actors, rules, conventions, processes, and mechanisms concerned with how relevant risk information is collected, analysed and communicated and management decisions are taken. Risk governance:

$\ddot{y} \quad$ Encompasses all the risk-relevant decisions and actions;

$\ddot{y} \quad$ Is of particular importance in situations where the nature of the risk requires the collaboration and coordination between various stakeholders (no single decision-making authority available);

y Calls for the consideration of contextual factors such as: (a) institutional arrangements (e.g. regulatory and legal framework and coordination mechanisms such as markets, incentives or self-imposed norms); and (b) socio-political culture and perceptions.

Governance and risk governance are important concepts for assessing and managing the implications of nanotechnology which looks set to become the next focus for heated debate about the relationship between new technologies, risk and sustainability (ETC Group 2003, Burke 2003). On the one hand, it promises smaller, lighter and faster devices using fewer raw materials and consuming less energy (Roco and Bainbridge, 2001). On the other hand, as the media hype surrounding the Prince of Wales' intervention in May 2003 has shown, there is genuine alarm about the disruptive potential of interventions at the nanoscale (Oliver 2003, Porritt 2003). The Prince is just the latest in a series of commentators to express fears about self-replicating nano-machines capable of smothering the world in 'grey goo' (Joy 2000, Porritt 2003, or for a current fictional account, Crichton 2002). These concerns about nanotechnology resonate with long-standing social science analysis of technology running 'out of control' (Winner 1977). Along with the relatively low levels of information about nanotechnology available, and the low public trust in industry and government (Macoubrie 2005), these factors are leading to an increasing risk of poor public perception. A particular concern is that insufficient formal and informal education will result in the misuse or inefficient application of nanotechnology. Education and training is a relatively long-term process that cannot be addressed by shorter term activities such as 'public relation' outreach.

A survey on current risk governance activities (Part A: The Role of government) in eleven economies and nanotechnology R\&D in 27 economies has been published by the IRGC (Roco and Litten 2005).

\section{DEFICITS OF THE RISK GOVERNANCE SYSTEM FOR NANOTECHNOLOGY TODAY}

\section{a. Types of Deficits}

The main deficit of risk governance for the first generation of passive nanostructures (nanoparticles, coatings, nanostructured materials) is the relatively low level of knowledge of the new properties and 
functions on toxicity and bioaccumulation, limited understanding of the nanomaterials exposure rates, and the gaps in the regulatory systems at the national and global levels.

The main deficit for the following generations (2nd to 4th) of nanoproducts (including active nanodevices, nano-bio applications, and nanosystems) is the uncertain/unknown evolution of the technology and human effects (for example, health, changes at birth, brain understanding and cognitive issues and human evolution), as well as a framework through which organisations and policies can address such uncertainties. More specifically, the following potential gaps can be identified:

- At this point in time the presence and characteristics of nanomaterials in the work place and in the environment are measured and assessed below optimal level. Some hazards and exposures are well under control, while others have not found the necessary attention (this deficit is dominant for the first and second generation). For example, there is no established system to monitor in situ nanoparticles in air, water, soil or biosystems. There is a need for metrology specific for nanoscale measurements for various nanoparticle delivery methods, both in the environment (particularly for ecotoxicity) and in medical fields (particularly for toxicity). Categorisation methods based on nanoparticle properties are not yet available in the pre-assessment phase where data has to be obtained for a range of nanoparticle sizes. Currently one has to scale down the complexity into manageable pieces using techniques such as decision trees. The existing risk assessment procedures and regulatory measures must be re-evaluated for nanoparticles,

$\circ$ Knowledge in EHS and sustainability including quantification of hazards, exposures and risk assessment (this deficit is dominant for the first generation). These are essential elements of governance processes for nanotechnology.

- There is a relatively fragmented governmental institutional structure and legal authority supporting risk governance of nanotechnology, with gaps and overlaps in the regulatory systems at the national and global levels (this deficit is true for all generations). For example, use of animal testing varies by country. End-of-pipe solutions concerning risk governance should be complemented with practices to improve the "behaviour" and responsibility (liability) of the different stakeholders in the process of innovation. Civil organisations are asking that the testing of nanomaterials be undertaken preferably by independent partners with greater transparency, and that the test results are disclosed.

- The simple cause-effect approach for single events should be replaced by a proactive, corrective approach with adaptive management for a system which is disturbed by given events (Roco 2005b). For example, the current environmental protection agencies regulations for ultrafine particles in air refer only to one measuring event. The life cycle, multiple nanoparticle interactions in the atmosphere, the effect of bioorganisms and the persistence of particles in the system are not considered. This is particularly necessary for nanotechnology applications belonging to the second to fourth generation.

- The long-term effects on human development are not well addressed, in part because of the limited scenarios available for the second to fourth generations of nanoproducts (relating to the third and fourth generation). For example, it is difficult to evaluate changes in human cognition as a result of understanding the brain nanostructure and applying nanomedicine. In another example, it is difficult to evaluate changes in life expectancy as a result of artificial tissues and organs generated using nanotechnology.

- A major deficit of nanotechnology risk governance today is the weak 'coordination' of nanotechnology safety issues between the different actors and stakeholders: science, industry, consumers, government regulators, civil society, and international bodies. For example, there is a gap between regulatory provisions, areas of relevance, and different standards for the same product. The US agencies generally regulate products, while in the EC the main regulations are on the process. There is an underdeveloped science/policy interface for nanotechnology which creates a communication gap between nanotechnology scientists, engineers and political decision makers. This deficit is true for all generations.

- Knowledge of nanotechnology implications by specialists and general knowledge of nanotechnology by the general public are limited in comparison to the rapid development of 
nanotechnology knowledge. The effectiveness of public debate of nanotechnology may depend on reducing this gap earlier. This deficit is true for all generations.

- There are proportionally lower resources for risk governance in the total R\&D budgets as compared to the higher level of perceived needs. Also, there is relatively low human capital available to address those issues. Research and education which supports safety and risk assessment should be better focused and levels increased. There are no published methodologies or standardised risk assessment tools (CBAN 2006). Current risk assessment tools may not be suitable for nano-sized materials due to toxicity and exposure unknowns. There is limited information on nano-sized particle behaviour in gas and fluid streams in environment, working place and biosystems. Exposure routes are not fully understood. This deficit is true for all generations.

- Regulatory uncertainty is hampering industrial innovation, particularly for small enterprises. There is an opportunity risk for the industrial sector in not developing nanotechnology products because of some concerns regarding future regulation. The inability to estimate the true risk profile of companies dealing with nanotechnology is resulting in a deficit in the risk transfer mechanism through insurance (Hett 2004). This deficit is true for the second to fourth generations.

- Cognitive deficit: bias in cognitive processes may affect risk governance. Examples are: status quo bias, overconfidence bias (people's overestimation of the degree of control over their environment and other people), and false consensus (seeking out opinions that confirm our beliefs and hypothesis) (Slovic 1992; Roxburgh 2003). Differences in perception affect public trust (one needs realism rather than excessive optimist or pessimism)This deficit is true for all generations but in particular is important for the third and fourth generations.

- The use of nanotechnology for potentially new weapons is a sensitive issue because of its secrecy, broad spectrum of possible applications, and unexpected consequences.

- The international agreements on nanotechnology are not sufficiently focused on broader issues of interest to humanity such as resources (water, energy, and food) and the environment. This deficit is particularly relevant for the third and fourth generations. International trade activities related to nanotechnology are not well established in key areas such as crossing national borders, export control, dual civil-military use, and the movement of experts and students. There is a gap in levels of control and power between those countries who are promoting nanotechnology, those who are implementing it, and those who will be impact by it (the latter of which do not have the infrastructure of the other two groups to efficiently respond to technological development). For example, the introduction of nanotechnology products in developing countries and the reduced or increased use of special metals may impact on commodity dependent developing countries (ETC Group 2005). This deficit is true for all generations. There is no international framework with which to address risk governance of nanotechnology at a global level and to provide consistency in areas such as reciprocal recognition of specific tests and regulations. This deficit is true for all generations.

Several of the gaps identified above are similar to other emerging technologies, and must be evaluated in the common context.

While the international benchmarking performed in over 20 countries in 1997-1999 (Siegel et al 1999) provided seeds for the formation of an international nanotechnology expert community, the policies and regulatory frameworks of various countries have remained fragmented until today. An international call for addressing global challenges in nanotechnology research (Roco 2001), and for addressing societal dimensions of nanotechnology at the international level (Roco 2003), have all contributed to the collaborative development of nanotechnology, but have had a relatively limited effect on nanotechnology governance efforts and the harmonisation of risk governance methods and structures. An APEC study (Tagart 2001) raised the issue of the opportunities for developing countries as early as 2001. However, given these opportunities there is also the danger that necessary precautions are not being taken in order to become the first one to grasp them. Nevertheless, this problem is beginning to be recognised and in June of 2004, the first broad international dialogue on responsible nanotechnology $R \& D$ brought together government leaders of national efforts from 25 countries and the European Community (Meridian 2004). The 2004 Dialogue yielded a set of principles, structured priorities, and recommended mechanisms for interaction and cooperation, including sharing data on 
environmental, health and safety issues. The follow-up meeting was hosted by the EC in July 2005 and the third Dialogue will be held in Japan in 2006.

As much as these new risks need to be addressed by science and risk managers alike, one should be aware that unintended consequences cannot be avoided particularly in a new technology reaching at the foundation of life and touching upon fundamental materials properties. A special category is caused by unexpected events for which it is difficult to calculate probabilities and which have surprise effects (so-called 'wildcards', Rejeski 2005). Such events may be intrinsic to the technology (such as malfunctioning of the equipment leading to new properties for nanostructures, or accidental release into the environment), or may be caused by external events (for instance, a natural disaster such as an earthquake, or a media event leading to a risky public perception).

\section{b. Knowledge Gap in Evaluating Impacts on Environment, Health, and Safety}

Current national and international governance systems reflect learned knowledge and experience developed in the research and practice of bulk and micro technology. It is as yet unknown whether the novel risk characteristics of nanotechnology applications can be adequately managed within these governance systems. The gap in knowledge is being addressed to some extent at national level through the accumulation of available data for the potential redrafting of legislation for substances with new characteristics e.g. the National Toxicology Program in the US (National Toxicology Program, 2005). However, there is a clear need for an international organisation to collect the information available worldwide; and to consider high-quality, globally applicable governance approaches to current and future potential risks.

The potential for risk has been widely considered, as has the potential for future applications. However the lack or scarcity of quantitative data - and the fact that risks are as yet complex, uncertain and ambiguous - results in a largely qualitative assessment of risk based on expert elicitation. Risk perception is also subject to extensive ambiguity. There is a general convergence of views on the short-term potential benefits to humankind e.g. innovative cancer therapies, which become more contested when considering long term 'benefits' such as longevity and birth modification. Perception of the risks attached to these applications is still more mixed as the more 'risky' applications are a long way from the product market.

Current applications, such as suntan lotion and self-cleaning windows, contain passive nanostructures and although they do not have the potential to transform society may have unknown consequences e.g. being able to enter the blood stream through the skin or enter the environment when washed off. The near-future 'active' applications and more long-term higher risk applications have been largely considered hypothetically and there is extensive divergence in the assessment considering both the potential for risk and significance for human health and the environment. For example, the ability for nanoscale structures to cross the blood-brain barrier can be considered to be of extremely high significance as this barrier is impenetrable to most substances and therefore little is known of the potential effects. However, an alternative view is that this ability is a benefit which could aid neural diseases such as Alzheimer's, and to exercise too much precaution over unknown effects would pose an even greater risk to society (Wildavsky 1990). There is a knowledge gap between what we need to know - especially concerning near-future 'active' applications and more long-term higher risk applications - and what we currently have available to us. Many applications are in the market now and some may be in the market within the next five years, and it is essential that scenario planning of potential levels of hazard and routes of exposure should be commenced. A prudent judgment can then be made of what governance structures and systems need to be in place should a particular scenario occur.

\section{c. Societal Infrastructure Deficit}

The current regulatory measures generally deal with a single event, cause-and-effect, and do not consider the life cycle of products, secondary effects and interactions with other events. The regulatory organisations and measures are fragmented from the area of jurisdiction, type of regulation (product, process, etc.), intervention levels, and national and international harmonisation of assessment and management procedures. An integrated governance approach for anticipatory and corrective measures is, however, necessary for an emerging technology that will have trans-boundary and global implications. The international collaboration deficit highlights the need for more aligned global infrastructural initiatives and harmonised risk regulations. Other deficits are in approaches for 
education and dissemination of knowledge, in gaps in the regulatory environment within a country and between countries, and in gaps between the portfolio of products and portfolio of waste disposal regulations.

\section{d. Communication and Engagement Deficit}

The public does not currently have a strong awareness of the nature and potential benefits and risks of nanotechnology. However this is likely to change rapidly as more products enter the market and the media becomes more active in publishing the applications and potential risks to a wider audience. Public awareness of risk tends to be higher if it is felt that individuals or societal institutions are not able to exercise personal or institutional control over it (e.g. lack of labelling on products containing an engineered nanostructure), if the technology is stigmatised (e.g. uncertain scientific knowledge and media hype); and if insufficient information is communicated to them concerning how risks are and can be controlled (IRGC 2005). It is therefore essential that the potential for risks and the governance systems being put in place to deal with these potential risks are communicated to the public as soon as possible. Trust between governments, businesses, academics, international organisations and the public needs to be enhanced though open dialogue and public involvement. As trust is highly related to the perception of performance and institutional agency, governance structures need to develop adaptable and flexible approaches to the governance of nanotechnology so that the benefits can be harnessed and unavoidable risks mitigated. The patience of the public may also be short while waiting for the new nanoproducts: the production of revolutionary new products typically takes over 10 years from the discovery.

\section{e. Role for the IRGC}

Governments and industry around the world are searching for the best governance practices; assessment and management models. EU, US, Japan and other countries are already discussing together with over twenty other countries modalities of international collaboration for safe development of nanotechnology (see Meridian Institute 2004). Yet these activities have not been focused on risk governance and several barriers have been noted. These barriers are partly due to the fear that international cooperation may be dominated by a few powerful countries, and partly due to the promise of reaping high economic benefit for being first in a market with high profit expectations. There is therefore a niche for an independent, international and multi-disciplinary organisation such as IRGC to contribute to the development of policy and regulations on nanotechnology. IRGC has identified a governance gap between the requirements pertaining to the micro- rather than the macrotechnologies. The novel attributes of nanotechnology demand different routes for risk-benefit assessment, appraisal of concerns and risk management. At present, nanotechnology innovation proceeds ahead of the policy and regulatory environment. In the shorter term, the governance gap is relevant for passive nanostructures that are currently in production and have high exposure rates; and for the 'active' nanoscale structures and nanosystems, which society can expect to be on the market in the near future. It is essential that advice and recommendations are provided to governments, businesses, scientific communities and international organisations in order that public awareness is stimulated by trust through open dialogue and action, rather than media hype and stigmatisation.

A candidate for looking at risk governance issues is the risk governance framework developed by the International Risk Governance Council (IRGC 2005) that provides an orientation for developing a best practice approach to risk governance for emerging technologies.

\section{THE IRGC RISK GOVERNANCE FRAMEWORK AND ITS SPECIFICS FOR NANOTECHNOLOGY}

\section{a. Purpose of the IRGC Approach}

The IRGC framework puts forward an integrated concept for risk governance that provides guidance for the development of comprehensive assessment and management strategies to cope with risks, in particular emerging risks at the global level. The framework integrates scientific, economic, social and cultural aspects and includes the effective engagement of stakeholders (IRGC 2005). The concept of risk governance comprises a broad picture of risk: not only does it include what has been termed 'risk management' or 'risk analysis', it also looks at how risk-related decision-making unfolds when a range of actors are involved, requiring coordination and possibly reconciliation between a profusion of roles, 
perspectives, goals and activities. The IRGC framework offers two major innovations to the risk field: the inclusion of the societal context and a new categorisation of risk-related knowledge.

The application of the IRGC framework to the risk governance of nanotechnology has resulted in two novel approaches: the categorisation of nanotechnology products and processes into four generations, and the use of two frames to evaluate the immediate and the future implications of evolving generation of nanotechnology applications.

Inclusion of the societal context: Besides the generic elements of risk assessment, risk management and risk communication, the framework gives equal importance to contextual aspects which, either are directly integrated in a model risk process comprising the above as well as additional elements or, otherwise form the basic conditions for making any risk-related decision. Contextual aspects of the first category include the structure and interplay of the different actors dealing with risks, how these actors may differently perceive the risks and what concerns they have regarding their likely consequences. Examples of the second category include the policy-making or regulatory style as well as the socio-political impacts prevalent within the entities and institutions having a role in the risk process, their organisational imperatives and the capacity needed for effective risk governance. Linking the context with risk governance, the framework reflects the important role of risk-benefit evaluation and the need for resolving risk-risk trade-offs (what are risk-risk-trade-offs?). Consideration of societal and cultural context in nanotechnology governance is essential because of the broad implications of the new technology on society (Roco 2003). The inclusion of social implications should be done using expertise specific for new sciences such as nanoscience (Collins and Evans 2002). Also, consideration should be given to the power relationships that are at work in society, and the sources of power and "levers" of power that different groups use to pursue their interests and objectives.

Categorisation of risk-related knowledge: The framework also proposes a categorisation of risk which is based on the different states of knowledge about each particular risk, distinguishing between 'simple', 'complex', 'uncertain' and 'ambiguous' risk problems.

$\ddot{y} \quad$ Simple risk refers to products where there is a clear cause and effect connection to behaviour of materials and their implications.

$\ddot{y} \quad$ Complexity refers to the difficulty of identifying and quantifying causal links between a multitude of potential causal agents and specific observed effects in a system or a system component. The nature of this difficulty may be traced back to interactive effects among these agents (synergism and antagonisms), long delay periods between cause and effect, inter-individual variation, intervening variables, and others. Scientists and technologists have still insufficient knowledge about the cause-effect chains regarding technological developments as well as their possible impacts in the various areas of nanotechnology applications. However, understanding the characteristics of a complex system component rather than the entire system may still be sufficient for designing risk management measures that are able to reduce or control risks that pertain to the entire system.

$\ddot{y} \quad$ Uncertainty. In the context of technological systems and their impacts, human knowledge is always incomplete and selective and thus contingent on uncertain assumptions, assertions and predictions (Functowicz and Ravetz 1993; Ravetz 1999). It is obvious that the modelled probability distributions within a numerical relational system can only represent an approximation of the empirical relational system with which to understand and predict uncertain events. It therefore seems prudent to include other, additional, aspects of uncertainty such as variability of impacted individuals and organisations, strategic responses to opportunities, system boundaries in modelling effects and plain ignorance (Morgan and Henrion 1990; van Asselt 2000 pp. 93138). All these different elements have one feature in common: they reduce the strength of confidence in the estimated cause and effect chain. If uncertainty plays a large role, and in particular the factors of system boundaries and ignorance, the estimation of technological impacts becomes fuzzy. The evolution of an active nanostructure may be typically uncertain within a given system. Uncertainty can often be addressed by collecting new data, developing better assessment models, and by singling out discrete cause-effect chains and the system components from the system as a whole. 
$\ddot{y} \quad$ Ambiguity may be a misleading because it has different connotations in everyday English language. In the context of nanotechnology it includes two aspects. Firstly, it denotes the variability of (reasonable) interpretations based on identical observations or assessments. What does it mean if, for example, nano-particles are able to penetrate brain tissues but do not cause any observable harm? Can this be interpreted as an adverse effect or is it just a bodily response without any health implications? Secondly, it denotes the variability of normative evaluation with respect to the tolerability or acceptability of observed effects on a given value or norm. Many scientific disputes do not refer to differences in methodology, measurements or dose-response functions, but to the question of whether the observed or assumed impacts violate or meet predefined values. Often it is also contested which values are (will be) actually of issue or are (will be) subjected to discussion and how essential these values are and for which groups. High complexity and uncertainty favour the emergence of ambiguity, but there are also quite a few simple and highly probable risks that can cause controversy and thus ambiguity.

The first three categories (simple/ complex/ uncertain) relate to the properties of our knowledge about nanostructures being able to generate specific hazards, while "ambiguity" is a property of knowledge about human responses to the hazard. For all risk generating nanoproducts we will have to consider the degree of complexity (simply to highly complex) and uncertainty (from certain to highly uncertain). Ambiguity as a property of the public response can be overlaid on any of the other two categories, and when this happens it changes dramatically the approach to dealing with the risk issues involved.

Turning to the field of nanotechnology, risk-related knowledge can be characterised currently as complex for passive nanostructures with new properties and functions, uncertain for active nanostructures and nanosystems, and ambiguous for large nanostructured systems and molecular nanosystems, although these categories could change as knowledge and public perception evolve further. Because nanotechnology development is an open, complex system, a suitable approach is using adaptive, corrective measures on the system instead of adopting simple cause-and effect measures for individual activities. The complexity, uncertainty and ambiguity dimensions interact in the domain of nanotechnology. Many diverse actors are dealing with this technology. On the one side there are the promoters, producers and embedders of nanoscience and nanotechnology (scientists, technologists, technology assessment experts and administrative promoters) also called 'insiders' (Garud and Ahlstrom 1997) or 'enactors' (Rip 2002, 2004). There are, further, interested organisations, pressure groups, individual consumers and citizens, public authorities at the demand side, also called 'outsiders' or 'comparative selectors'. The diversity of the involved actors inevitably makes innovation in the domain of nanotechnology a social learning process (Tait and Williams 1999, Williams and Russell 2002).

The framework's risk process, or risk handling chain is illustrated in Figure 2. It breaks down into three main phases: 'pre-assessment', 'appraisal', and 'management'. The appraisal step includes traditional risk assessment and the novel element of concern assessment. Both elements of the appraisal process are directed towards the best scientific analysis of physical impacts as well as the social impacts that one can expect from the application of the technologies in question. An interim phase, comprising the 'characterisation' and 'evaluation' of risk, is placed between the appraisal and management phases and, depending on whether those charged with the assessment or those responsible for management are better equipped to perform the associated tasks, can be assigned to either of them - thus concluding the appraisal phase or marking the start of the management phase. Risk evaluation refers to the judgment of tolerability or acceptability of a given risk. The risk process has 'communication' as a companion to all phases of addressing and handling risk and is itself of a cyclical nature. However, the clear sequence of phases and steps offered by this process is primarily a logical and functional one and will not always correspond to reality.

For nanotechnology, there are significant differences between various areas of relevance and between the four generations of nanotechnology products. A critical aspect is knowledge development for the field. A major challenge is that decisions and implementation actions (for R\&D, infrastructure investments and regulations) need to be done before most of the processes and products of nanotechnology are known.

The following sections will follow the risk governance framework step by step and explain in which way the framework could help to establish more effective and publicly responsive governance structures for dealing with potential nanotechnology applications in terms of risks and benefits. 
Figure 2. Steps in IRGC risk assessment and management framework for nanotechnology (NT); NS denotes nanostructures.

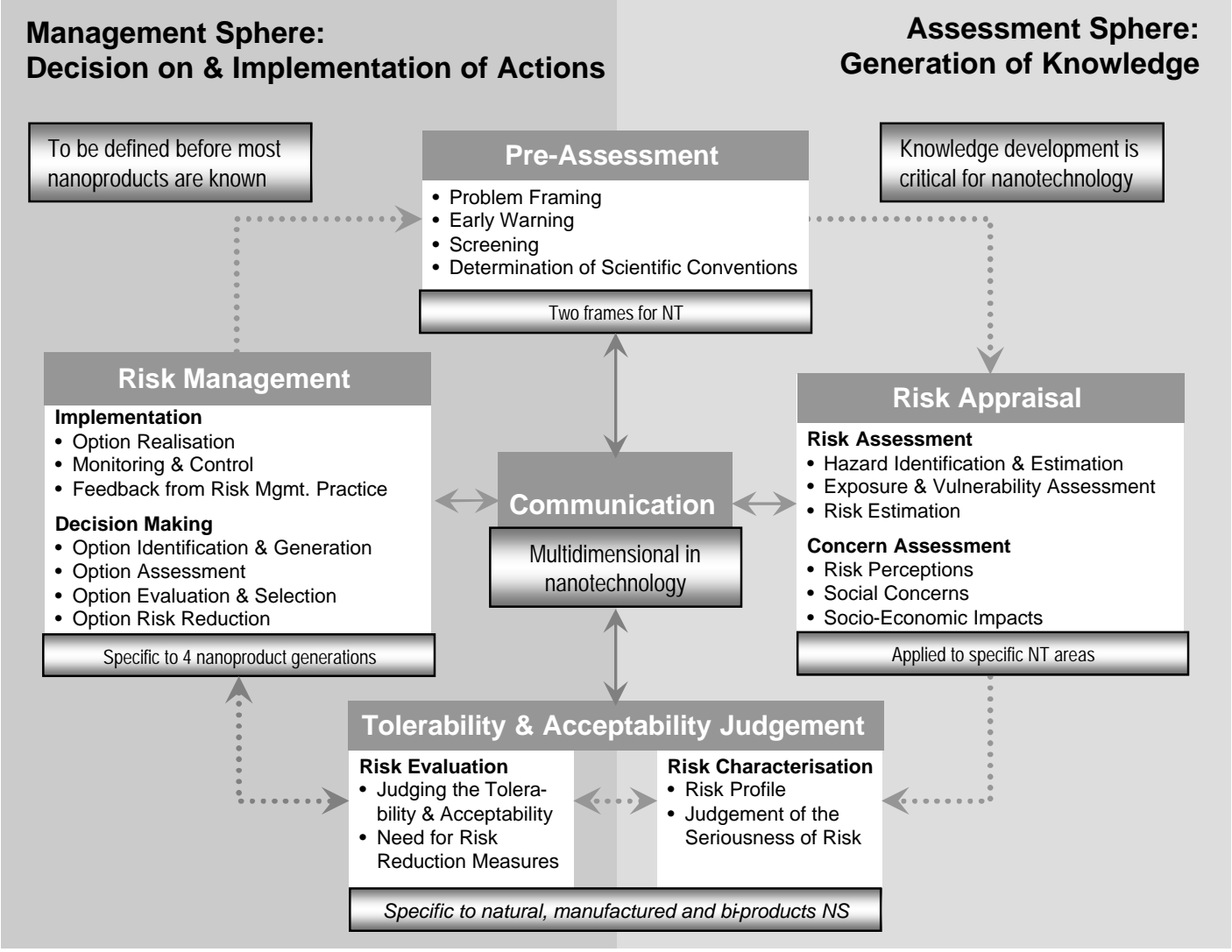

\section{b. Pre-assessment: Two Frames for Nanotechnology Risk Debates}

The IRGC framework addresses wider governance issues pertinent to the context of a risk and the overall risk process, thus acknowledging the many different pathways that different countries or risk communities may pursue for dealing with risk. Pre-assessment builds on the observation that collective decisions about risks are the outcome of a 'mosaic' of interactions between governmental or administrative actors, science communities, corporate actors and actors from civil society at large. Many interactions are relevant to only same parts of the process. The interplay of these actors includes public participation, stakeholder involvement and the formal (horizontal and vertical) structures within which it occurs.

A systematic review of potential benefits and risks of an emerging technology needs to start with an analysis of what major societal actors, such as, governments, companies, the scientific community, NGOs and the general public defines as areas of concern or impacts that they will label as risk problems (rather than opportunities or innovation potentials, etc.). In technical terms this is called 'framing'. Framing in this context encompasses the selection and interpretation of phenomena as relevant risk topics (Tversky and Kahneman 1981; van der Sluijs et al. 2003; Goodwin and Wright 2004). With respect to nanotechnology we have identified two major frames under which the risks have been discussed in the present debate:

$\ddot{y} \quad$ Frame 1. The context of classic technology assessment looking into the impacts derived from the application of nanoparticles and other passive nanostructured materials in different areas of application (such as paint, cosmetics, food, and coatings). This frame is most suitable for issues related to the first generation of nanoproducts (passive nanostructures, Figure 3 ). The property or behaviour of some passive nanostructures may be complex, typically for system components. Depending on the application there will also be more or less uncertainty when predicting positive or negative impacts for the economy, environment and society. 
Figure 3: Strategies as a function of the generation of nanoproducts: application to Frame 1 and Frame 2

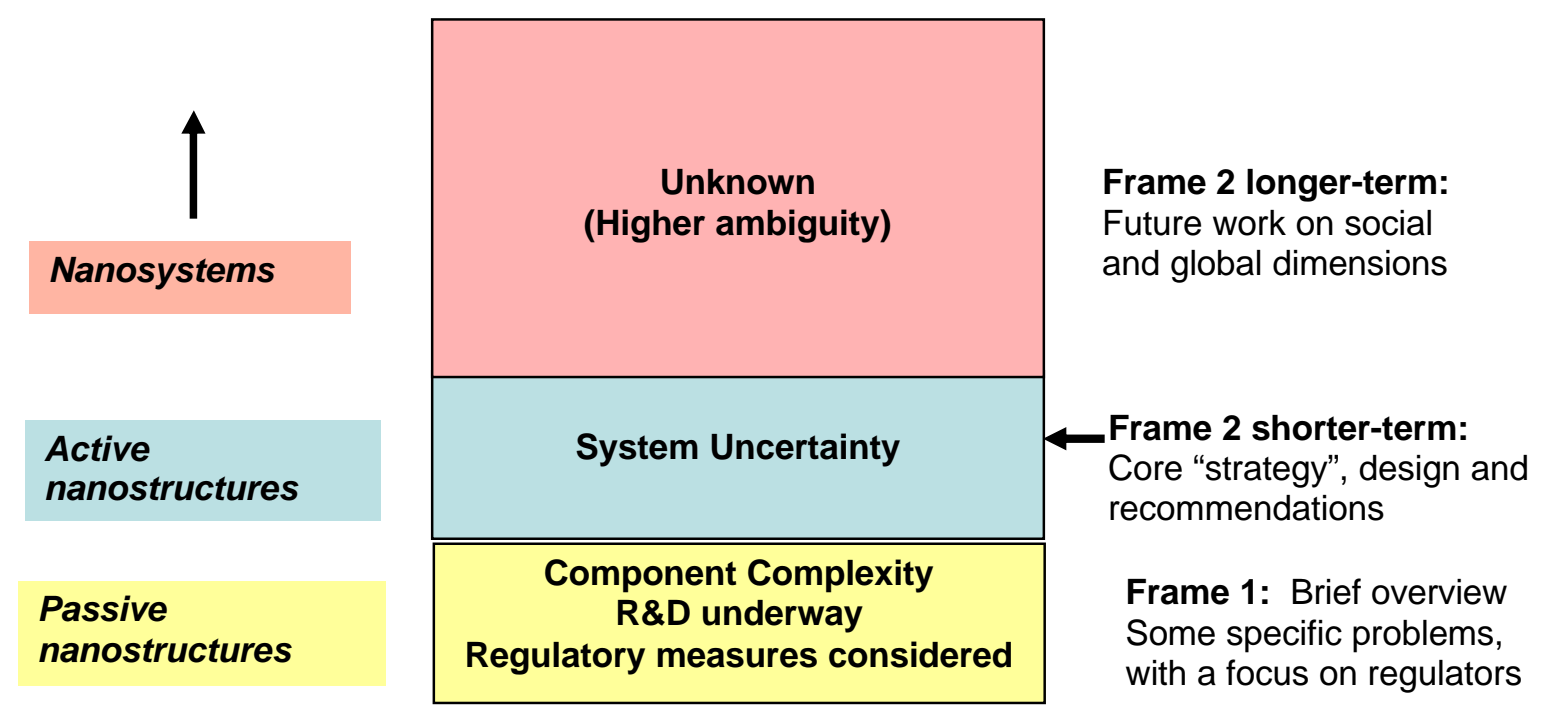

NT application areas

$\ddot{y}$ Frame 2. The context of social desirability of innovations looking into processes of modernisation, changes in the interface between humans and machines/products and ethical issues of the boundaries of intervention into the environment and the human body. This frame addresses better the issues related to the future generations of nanoproducts (active nanostructures and nanosystems, Figure 3 ) and long-term implications of nanotechnology (Roco, 2004a). The behaviour of active nanostructures and systems typically changes in time and is complex: it may be uncertain for many system components and tends to be uncertain for the system as a whole (at least from today's perspective). Frame 2 is more likely to be associated with higher degrees of ambiguity by considering current knowledge and perspective on nanotechnology.

The context for Frame 1 (see Figure 4) is focused on complexity within system components where the passive nanostructures are applied. There is a scientific debate on the implications of the novel aspects of nanoparticles on human health and the environment. The major actors here are scientific communities, product and process developers, governmental bodies and local institutions including regulatory agencies, NGOs, ad hoc commissions, and technology assessment institutes. The goal of this frame is to understand and recognise potential health risks before they materialise in larger quantity. The evidence in this debate relates to toxicological experiments, simulation and monitoring of actual exposure. A major conflict lies in the question of how much precaution is necessary when applying these nanoparticles. Several NGOs advocate a very precautionary approach by which application is restricted to highly investigated products while others, such as most industries, favour a slow penetration approach combing plausibility checks (do we expect anything more serious than what we have already?) combined with constant monitoring.

The flowchart in Figure 4 suggests the main steps in the research and regulation of nanomaterials implications once released either in the environment or at the working place. The implications affect people, biosphere and surrounding infrastructure. The risk governance should ensure safety in all those areas of the outlined close loop. 
Figure 4. Environmental, health and safety (EHS) research and regulatory for nanomaterials (Frame 1): key physico-biological processes and decision steps during the life-cycle of nanomaterials released either in the environment or at the working place (modified from Roco (2005b))

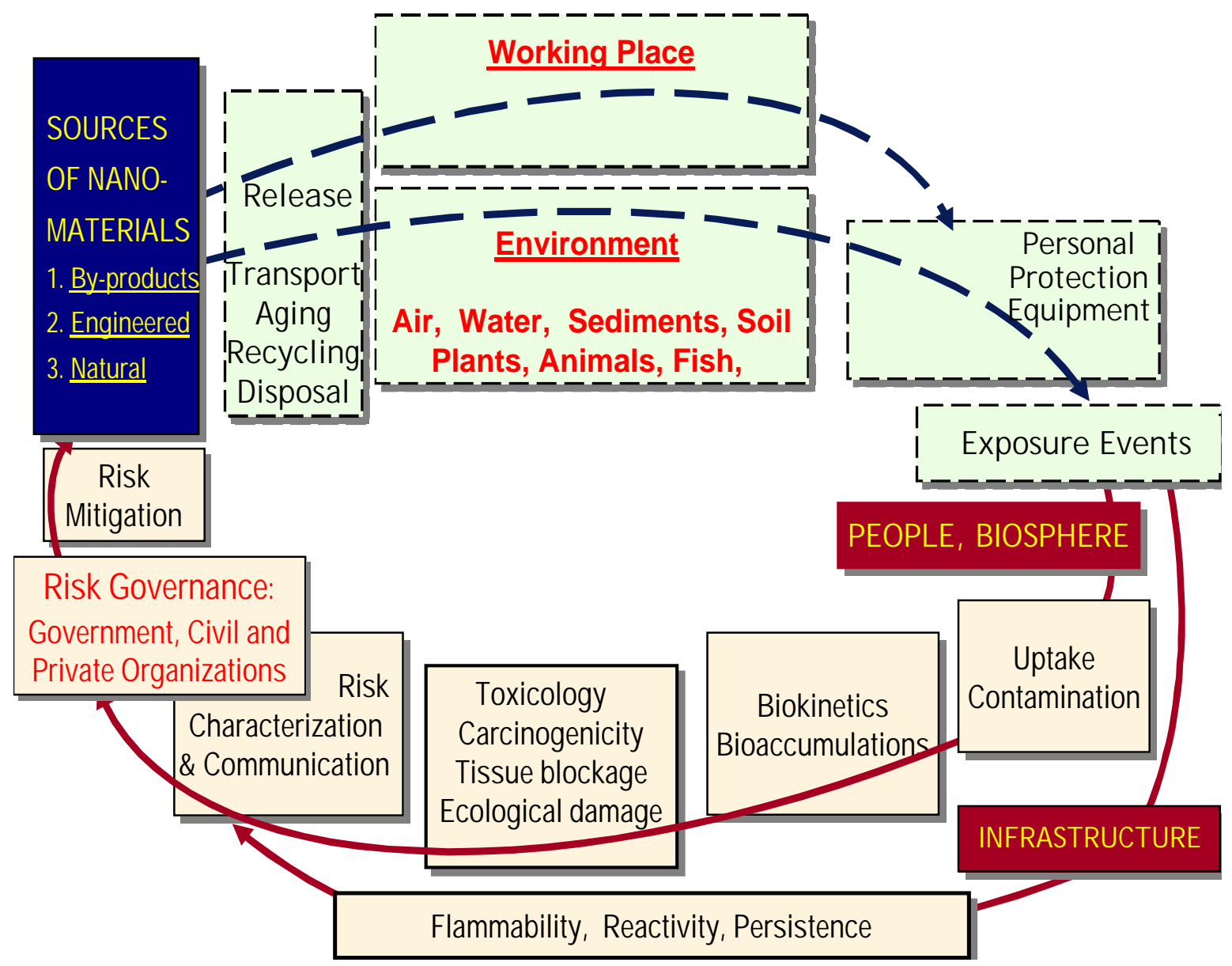

The context for Frame 2 (see Figure 5) is more complicated. Component complexity is increasing and the dynamic behaviour and multifunctionality of the nanostructure may lead to uncertainty within the respective system. It is also directed towards ambiguity. The main argument is that nanotechnology represents a new class of processes and applications that may threaten human identity; speed up the pace of modernisation beyond the speed that human societies can cope with; and transform our environment into directions that nobody can realistically predict. This debate, focusing on what is desirable, leads different actors to assess technological trajectories on criteria that had not previously been considered. Inversely, discussions about what can be technologically possible can steer the formation of judgements about desirable societal changes (Grin et al., 1997; Grin and Grunwald 1999; Grin 2004; Goorden 2003). The debate on nanotechnology seems to pursue both directions. On the one hand, new applications and future visions of the technology provoke new ideas and reflections about human identity and the mind, while, on the other hand, new ethical considerations about sustainability direct nanotechnology research into applications that were not originally pursued by the engineering community.

The flowchart in Figure 5 suggests that the 'open system' loop begins with nanotechnology knowledge creation leading to new products, health and cognition developments. By using scientific, technological and social scenarios one may estimate the long-term potential implications on people, biosphere and surrounding infrastructure. On this basis, risk governance and public policies could be formulated which address the further development of nanotechnology and evaluate its risks. In turn, this may lead to new R\&D programmes, infrastructure growth, suitable regulatory measures and standards, and institutional capacity to respond to uncertainty. The new knowledge created to lead to new outcomes is generally different from the previous cycle ("open system") 
Figure 5. Risk governance for active nanostructures and nanosystems (Frame 2): key decision processes in the open loop approach (modified from Roco (2005b))

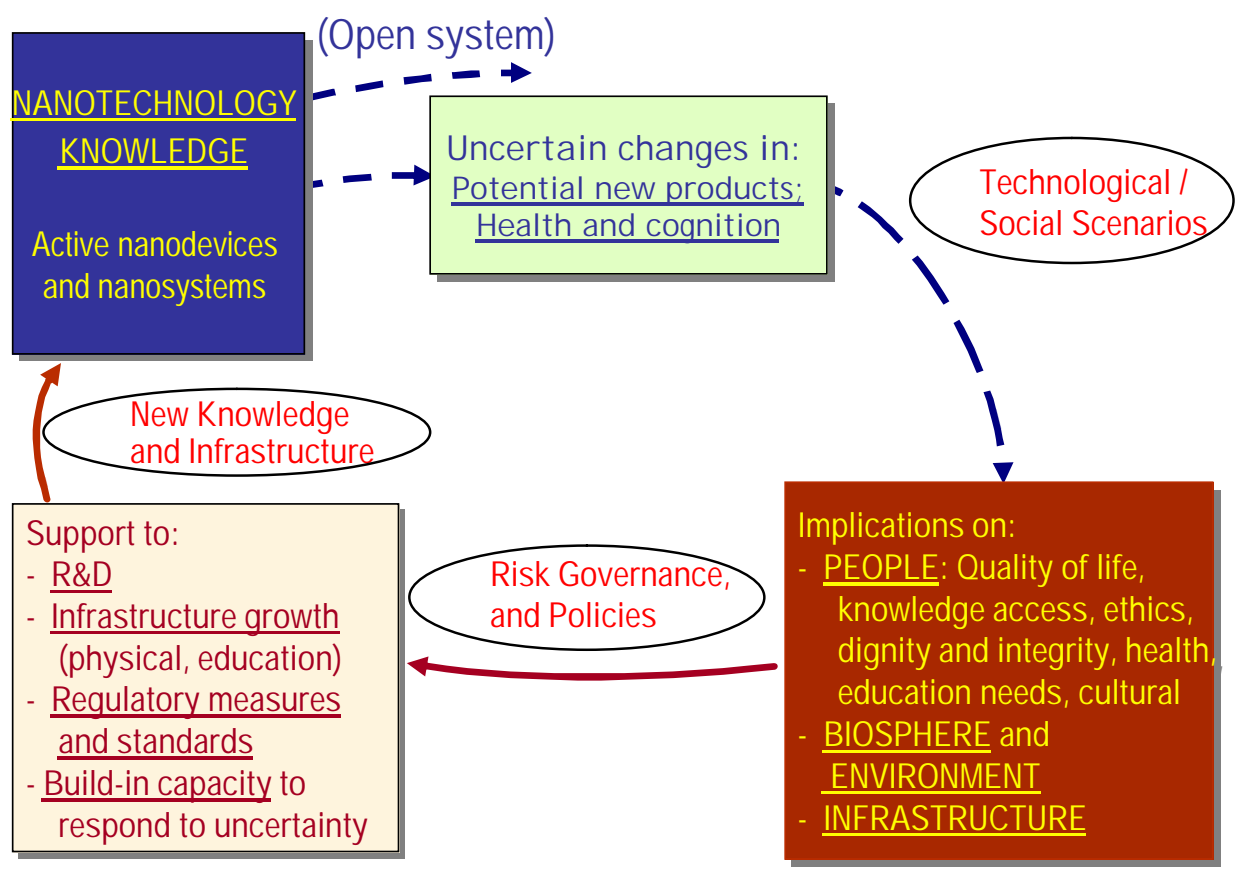

Ethical implications of nanotechnology development on risk governance are particularly important for frame 2. Stakeholders must achieve understanding and engage issues of ethical and social responsibility with regard to individuals and affected institutions. Societal implications of distribution of benefits and unexpected consequences of the new technology may create tensions if not properly addressed (Weil 2003, Baumgartner et al 2003).

The concern of frame 2 is therefore characterised by a mixture of beliefs, values and visions that are not exclusively linked to nanotechnology but are, at least partially, associated with it. This frame is shared by many cultural opinion leaders, religious groups, parts of the humanities and social sciences, and often individuals who are disappointed with the direction of technological and social change. Traditional impact assessment or risk analysis will have no bearing on the arguments that are exchanged in this debate (Tait 2001). The evidence that is part of this debate refers to narratives that show plausible (or implausible) links between social and perception threats and combination of technologies including nanotechnology. Examples are neurochips to be implanted in the human brain, nanomachines used in warfare, plants with biochips, and other "futuristic" applications. The main message is: 'Stop this process before it is too late'.

It is important in the pre-assessment phase and beyond to distinguish these two very different frames, 1 and 2, and understand the linkage between them. Each frame demands very different forms of handling and appraisal. In particular, the selection of management strategies needs to be adapted to the characteristics of the frame. At the same time, an incident in frame 1 (for example, accidental exposure leading to a visible health impact) may serve as a promoter for transmitting the concerns to frame 2 (same may be true from frame 2 to frame 1) assuring the attention of a larger audience. It may trigger a chain reaction starting with a given health event, leading further to the image that modern societies cannot even deal with simple health hazards and cumulating in the conviction that humans should refrain from such complex technologies since they cannot control them. An additional risk challenge is the effect of occasionally occurring hazards.

The other areas of pre-assessment are close related to the issue of framing. Early warning signals can be assigned to watching potential impacts of nanoparticles and/or watching the societal debate and the evolution of concerns with respect to the ambiguity of the nanotechnology applications. Depending on the dominant frame, the third step "pre-screening" is also affected. The risks of nanoparticles will be allocated to the classic risk assessment and management route. The second frame looking into 
societal and ethical implications and into nanotech's role in a technological culture requires risk analysts to focus on the concern assessment route with a strong participatory element. Evaluating the acceptability of nanotechnology as a promoter of modernisation cannot be done on technical, medical and ecological criteria alone. Here social, cultural, religious and ethical views need to be included and integrated. Finally, the scientific conventions (fourth step in pre-assessment) also depend on the respective reference frame. The usual toxicological and epidemiological methods need to be applied in the first frame, scientific methods of concern analysis, empirical attitude and value research, and ethical reasoning are more appropriate for the second frame (Roco and Bainbridge 2003 and 2005, EC 2004).

Structuring risk governance into the two frames is important to enable the development of critical knowledge for effective risk management. If they are not decoupled, it will impede the generation of targeted data for improved risk management of Frame 1 nanomaterials. Meeting the research needs required for Frame 1 necessitates an approach that is based on classic and modified research instruments and requires cooperation among technical, medical and ecological disciplines. The research scope can be contained to established technology assessment procedures. So, timely and reliable results can be expected. The need for further research and assessments does not interfere with the present speed of diffusion. Research for Frame 2 questions, however, require a more holistic and transdisciplinary approach. This includes a strong social science involvement, the incorporation of stakeholder preferences, and intense reflections by legal and ethical scholars. It should be avoided to have the two frames mixed because they rely on different research and decision making pathways.

\section{c. Risk Assessment}

The assessment process in the IRGC framework (see figure 2) consists of two parts: risk assessment and concern assessment. They fit well the dualism of frame 1 and frame 2 that have been discussed above. The first assessment step covers the usual steps of:

$\ddot{y} \quad$ Hazard identification and estimation

$\ddot{y} \quad$ Exposure and vulnerability assessment

$\ddot{y}$ Risk estimation

$\ddot{y}$ Conclusion on major challenge for risk assessment applied to specific nanotechnology areas (categorisation of risk with regard to degree and cause of complexity, uncertainty and/or ambiguity).

As explained in the first section of this paper, nanostructures and particularly nanoparticles not only exhibit new properties which one can make use of in many industrial and pharmaceutical applications, but also there is already evidence that these chemical, physical, and biological properties may have possibly harmful consequences for human health, nature and environment. However, the existence of anthropogenic and natural nanoparticles has been known to science for a long time; certain nanoparticles have been characterised and their effects are well established in the scientific literature. In spite of this limited knowledge, one can predict that the development and use of the first generation of nanoproducts will largely increase the variety of species of nanoparticles, their density in our human and natural environment and the probability for human beings to get into physical contact with them or to incorporate them.

In order to structure the problem for risk analysis that contains uncertainty and complexity, it was proposed using expert information and influence diagrams for the EHS effects of nanomaterials to be studied (Morgan, 2005). The following paragraphs summarise the results of the present studies on different risk categories.

\section{How can the risks be characterised?}

The increased reactivity of some nanostructured materials, a size many times smaller than the human eye can see, and the new physical and chemical properties and functions of nanosystems, will result in the potential for newly emerging risks, such as, penetration into and reaction with the human body; release into and reaction with human surroundings (e.g. work place, environment, and on disposal); changes in degradability and persistence in the environment; and longer term societal issues such as, social control and nanoscale-based genetic changes. These risks also have the potential to be global in nature, for instance, economic and military imbalances and widespread environmental contamination. In addition 'active' nanodevices may evolve in the environment and start self-propelling activities where they are released which may require additional risk governance management measures. 


\section{Health Risks}

From the beginning of the debate on nanotechnology, there has been an intense discussion on the potential risks (Wolfson 2003). This subject has not only been debated by nanoscientists but also increasingly by representatives of the social sciences and humanities (See e.g. Roco and Bainbridge 2001 and 2005; Fogelberg and Glimell 2003; and Johannsson 2003), by NGOs as well as by social and political institutions.

In general, free nanoparticles and other nanostructures do raise health and safety concerns. One reason is that these smaller particles have a much larger surface to mass ratio compared to the larger particles; they are likely to penetrate cells in the body and take on different structures than they would have at their larger scale. Their chemical reactivity and bio-activity may vary with particle size. The risk of accumulation in cells and toxicity depend on the exposure route, material and size (Maynard 2005).

Since all of the complex relationships are not well-known it is difficult to evaluate the toxicity of novel nanoparticles coming from these new technologies. Most of the assumptions on the potential adverse health impacts come from emergence of evidence in air pollution, in the effects from the inhalation of welding fumes and extrapolation from the extensive body of knowledge on the health effects of existing micrometer sized particles. There are, however, a number of long-term studies underway which should clarify the current assumptions. One theory suggests that the finer particulate in air pollution, those in the nanoscale range, may be responsible for increasing blood coagulation, leading to increased blood viscosity and causing cardiac ischaemia. Other hypotheses include an effect on neutrophil deformity and atherosclerotic plaque progression and destabilisation.

There is also a general picture that is emerging from animal studies - that on a mass dose basis, pulmonary toxicity is enhanced when particle size is reduced from the micrometer to the nanometre range. The increase in the materials' toxicity appears to be partly linked to the increase in the particles surface area (causing a catalytic effect and generating free radicals); however, it also seems that there is a difference in toxicity, depending on the materials. That is, some materials in the nanometre range are more toxic, leaving the final verdict on a material's toxicity to a case-by-case basis - for example, single high exposure to non-fibrous, non-cytotoxic particles, like carbon black, titanium dioxide, talc, can produce transient pulmonary inflammation. Following repeated exposure, there appears to be a risk of sustained inflammation, lung damage with hypertrophy, epithelia hyperplasia and interstitial fibrosis due to overload (exceeding the capacity of the alveolar macrophage's capacity for phagoctose leading to the secretion of inflammatory mediators).

Exposure to non-fibrous, cytotoxic particles, like silica are more likely to directly affect the alveolar macrophages due to its surface area chemistry and free radical generation potential (production of oxidative stress). For example, toxicological studies have shown that low exposure to micrometersized particles of quartz cause severe lung inflammation, cell death, and fibrosis. It has also been shown to cause tumours in rat studies. Current thinking suggests that these effects are related to the surface of the quartz, which is reactive and generates free radicals leading to oxidative damage. Studies on exposure to coal and silicates have found that similar effects can be expected if the dose is sufficiently high causing overload, and that this relates to the total surface area of the particles inhaled. In essence, cells and organs may demonstrate toxic response even to non-toxic substances when they are exposed to high enough doses in the nanosized range.

Concern relating to the exposure to nanosized fibrous particles is similar to those for non-fibrous particles, in this case, pulmonary toxicity and or cytotoxicity. The history of asbestos is still fresh in our mind and there is fear that nanosized fibres may introduce similar problems. Fibres such as those coming from carbon nanotubes could also cause a problem, not only due to their shape and dimension, but also because of their potential to be combined with iron or other metals. The addition of these metals could cause catalytic effects having free-radical-releasing pro-inflammatory properties. Current animal studies using nanosized particles, such as titanium dioxide, barium sulphate, metallic cobalt and metallic nickel, found that metallic nickel demonstrated statistically significantly greater inflammation responses than either cobalt or titanium dioxide and that cobalt was more inflammogenic than titanium dioxide. Nickel and cobalt but not titanium dioxide caused lipid peroxidation.

There has also been some concern voiced about the possibility for nanosized particles to translocate to liver and other organs; however this may be dependent on the differences in exposure conditions, chemical composition and particle size. 


\section{Risk of changing human condition}

Development of active nanostructures and nanosystems and hybrid bio-nanostructures has raised concerns about human development risks. These include devices which interface with human tissue and nervous system, artificial organs, genetic modification, brain and body control, hybrid viruses and bacteria, as well as economical and cultural development.

\section{Risk of explosion}

Traditionally, it is known that dust explosions can occur in manufacturing sites that use fine particles of sugar, flour, animal feed and in operations that produce sawdust, organic chemicals plastics, metal powers and coal. The major factor influencing the ignition sensitivity and explosion violence of the dust cloud is the size of the particle or the total surface area per unit volume. Generally, as the particle size decreases the specific surface area increases, and the dust explosion and the ease of ignition also increases, although this effect is not linear and for some materials the effects plateaus at the smaller size range. There seems to be no lower particle size limits established below which dust explosions couldn't occur.

It may be possible that the increased surface area of nanoparticles could also increase the likelihood that they become self-charged, and ignite. Nanopowders, again, because of their large specific surfaces areas, may become highly charged in use. There is also concern that they may persist airborne longer, as well as be harder to detect. Unfortunately for now, there appears to be no data on the explosion characteristic for nanopowders, and the Health and Safety Executive of Great Britain (HSE, 2004) suggests that extrapolation of the data for larger particles to the nanosize range cannot be accurately done due to the changes in both the chemical and physical properties. The law of quantum physics comes into play at the smaller size of particles, and the behaviour of the surface starts to dominate the bulk behaviour of the material. For example, some materials that are conductors of electricity become insulators at the nanosize range.

\section{Ecological risk}

Nanomaterials may affect ecosystems through the activities surrounding their fabrication or their release into the environment during production, use or disposal. Their impact may be important because of their size, reactivity, bioaccumulation and persistence. However, one must analyse each type of application individually. Robichaud et al. (2005) have shown that the relative environmental risk during fabrication of single-walled nanotubes, bucky balls, one variety of quantum dots, alumoxane and titanium dioxide nanoparticles, was comparatively low in relation to other common manufacturing processes now in use. In another example, Oberdorster et al. (2004; 2005) found situations when nanoparticles reach the brain of living organisms. Colvin et al. (2003) have shown that surface treatment of nanoparticles may reduce or eliminate the toxic effect of some engineered nanoparticles.

\section{What does that mean for risk assessment?}

Although the steps of assessment will follow the traditional path of hazard identification and estimation, exposure and vulnerability assessment and risk estimation, the specific methods for conducting these analyses might be different from the normal toxicological routines. For example, the traditional filter and gravimetric methods used for particulates cannot be used for particles at this range, and the currently available technology is rather expensive. One method used to sample for nanoparticles is the low-pressure nano-cascade impactor, which uses five impactor plates from sizes between 10 to 100 $\mathrm{nm}$. Another method uses a filter and passive sampler, however, it seems that the sample has to be sized and counted by transmission electron microscope, which makes the lab analysis rather expensive.

\section{d. Concern Assessment}

In addition to risk assessment, the IRGC model includes a concern assessment. This is particularly important for dealing with the frame 2. What do we know about public concerns when it comes to nanotechnology?

Although nanotechnology is still an emerging field, the battle lines being drawn up around it are analogous to those involved in earlier controversies over nuclear power, GM crops, biotechnology and mobile phone masts, and are likely to change rapidly in response to particular developments (Tait, 2005). Lining up on one side are those who see nanotechnology as an area of exciting potential for the economy, society and the environment. Challenging them are those who remain sceptical about the possible vested interests lying behind the science, the questionable nature of the commitments bound 
up in R\&D processes, and the known and unknown risks that could be unleashed by its application. Since many new technologies experienced a strong public opposition after their often euphoric introduction, it is important to understand in advance potential public reactions and potential mobilisation effects by relevant social groups.

Nanotechnology and its implications have been analysed from a societal perspective (Roco and Bainbridge, 2001 and 2005), and from an NGO perspective (ETC 2003; Arnall 2003 (for Greenpeace); Komm-paassion Group 2004, Environmental Defence 2005) with respect to the ethical, legal and other social issues (ELSI). Furthermore, governmental organisations have established/funded technology assessments of nanotechnology. Key "society structural" risks include the regulatory environment (risks may be raised by gaps in the regulatory system), the portfolio of processes and products used in industry, and waste handling policies. Several "wildcard" risks include accidents, terrorist attacks, use of military nanoproducts (Altmann 2005), and impact mass media products (movies, books, etc.). One of the more notable contributions to the social risk debate is a report by the ETC Group, a Canadian NGO, which hit the headlines in February 2003 with its assessment of the potential dangers of nanotechnology. Demanding a moratorium on commercialisation, the report warns of a Pandora's Box of potential hazards, ranging from "nanoparticle contamination, to grey goo and cyborgs, to the amplification of weapons of mass destruction" (ETC Group 2003). In the same month, the UK Government's Better Regulation Taskforce called for the development of a new regulatory framework for nanotechnology, and for an early and informed dialogue between scientists and the general public about its impacts (Better Regulation Taskforce 2003).

For improving our understanding of the likely responses of the population and particularly major NGOs, concern assessment is linked to risk perception and stakeholders concerns. It is necessary to investigate the evolving socio-cultural and political context in which research at the nanoscale is conducted, the societal needs that nanotechnology may satisfy, and the popular images that experts, politicians, and representatives of the various publics associate with nanoscience and nanotechnology. The past research on public attitudes and political mobilisation has demonstrated that the effectiveness of public protest does not depend so much on the number of people concerned about a technology but rather on the composition of the groups that are willing to act publicly in favour or against the implementation of such technologies (Hampel et al. 2000).

Public perception of technological risks depends on two sets of variables: the first set includes the well-known psychological factors such as perceived threat, familiarity, personal control options, and positive risk-benefit ratio (Slovic 1992; Boholm 1998). The second set includes political and cultural factors such as perceived equity and justice, visions about future developments and effects on one's interests and values (Wynne 1984; Tait 2001; Renn 2004a). While the first set of components can be predicted to some degree on the basis of the properties of the technology itself and the situation of its introduction, the second set is almost impossible to predict. The social, political and cultural embedding of a new technology is always contingent on situational, randomly assorted combination of circumstances that impedes any systematic approach for anticipation. Within the second evolving frame, however, the symbolic nature of nanotechnology representing fast modernisation, efficiency and artificiality, provides us with some hints of where the debate might go in the future.

Comparative qualitative studies have been conducted to investigate the public perception of nanotechnology (e.g. Gaskell et al. 2004), and several approaches from a broader Science, Technology and Society (STS) perspective analyse the potential social concerns and societal impacts of nanotechnology applications, e.g. Bainbridge (2002b), Fogelberg and Glimell (2003), Johansson (2003), Sweeney et al. (2003), Wolfson (2003), Cobb and Macoubrie (2004), Spinardi et al. (2005), and Williams (2005). Looking at the empirical results in the United States and Europe so far, it is interesting to note that the concern linked to the second frame (about the science-fiction notion of selfreproducing nano-robots or other more exotic applications of nanotechnology that could harm humans directly) has been rarely found in the few surveys conducted until today (the theses of Joy, 2000, and others have not found much resonance in the public). Rather, critical remarks centre on the concern that nanotechnology would be misused by some people to harm other people, exacerbating existing social inequalities and conflicts. In contrast, most respondents associated quite a number of direct but non-specific benefits and found a number of ways to express confidence that nanotechnology would help human beings achieve legitimate goals (Bainbridge 2003).

In order to understand the risk perception side of nanotechnology large opinion surveys are only of limited value. The main problem here is that for more than 90 percent of the respondents in European as well as US surveys the term nanotechnology has no meaning or has weak meaning and evokes 
educated guesses at best (Roco and Bainbridge 2001). Even if the term is explained to the interview partners, the response is a direct reaction to the verbal stimulus and thus more an artefact of the questionnaire than a valid representation of a person's attitude. A more promising method would be to conduct focus groups in which proponents and opponents of nanotechnology would be given the opportunity to develop their arguments in front of representatives of the general public or selected groups and then ask the respondents to share their impressions and evaluations. Several of these studies are underway, partially combined with citizen juries or citizen panels, which are asked to investigate the public's preferences for regulatory actions after they have been informed about the likely impacts of nanotechnology.

A recent survey of the US public using a method of informing the participants before asking their opinion supports the general impression of an attentive public that welcomes nanotechnology as helping the economy to prosper but also has deep suspicion about industry and distrust in government (Macoubrie 2005). The study concludes with some major findings:

- Major benefits are anticipated by the public and welcomed

- Public wants to be included in the regulatory process

- There is a lack of support for a ban on nanotechnology, but there is a high demand for effective regulation

- There is low public trust in government: participants believed the trust situation could be improved by more testing before products are approved for free distribution and by providing more unbiased information to the public

- The influence of media on public attitude formation is still low; most people have not heard about nanotechnology before

- Industry is seen with a high degree of suspicion

The report recommends that under the present low trust situation industry and regulators need to place special effort on improving transparency and including the public in regulatory decision making.

\section{e. Risk Characterisation}

Four levels of knowledge characterisation are presented in Table 1.

\section{f. Risk Evaluation}

Risk evaluation comprises three major steps for both frame 1 and 2 :

- Scientific (evidence-based) 'risk profile' focused on risk assessment and concern assessment

- Societal (value-based) balancing of benefits and risks (including societal needs, contribution to quality of life, contribution to sustainability, potential for substitution and compensation, policy imperatives, choice of technology, and overall risk-benefits balance)

- Conclusion on whether risk is acceptable, tolerable, unacceptable or not defined.

Corporate risk managers as well as regulatory agencies have the task to collect all of the information from the assessment processes and make a judgement about the balance between the potentially negative and positive impacts. Such a judgement cannot be made for nanotechnology as a whole although some advocates of the second frame would like governments to make such sweeping generalisations. It is rather necessary to look at each application, collect what is known about the impacts and then delineate a judgment of acceptability or tolerability.

The term 'tolerable' refers to an activity that is seen as worth pursuing (for the benefit it carries) yet it requires additional efforts for risk reduction within reasonable limits. The term 'acceptable' refers to an activity where the remaining risks are so low that additional efforts for risk reduction are not seen as necessary. If tolerability and acceptability are located in a risk diagram (with probabilities on the $y$-axis and extent of consequences on the x-axis), the well known traffic light model emerges (Figure 6). In this variant of the model the red zone signifies intolerable risk, the yellow one indicates tolerable risk in need of further management actions (in accordance with the 'as low as reasonably possible' - ALARP - principle) and the green zone shows acceptable or even negligible risk. The grey area illustrates the border lines: the first border identifying the area where one gets close to certainty (probability $=1$ ) and the second where one gets close to indefinite losses. In the first case most legal documents and ethical schools prohibit the tolerance of risks that will lead to certain losses of life. However, certain losses of artefacts, money or other material assets may be tolerable. The same is true for indefinite 
losses. Many ethicists would not accept the possibility of an indefinite loss of human lives even if the probability were extremely small. This is not true for other types of losses. Therefore we leave these boundary areas undefined.

\section{Figure 6. Acceptable, tolerable, intolerable and undefined risks relative to benefits (Traffic Light Model, a stakeholder perspective)}

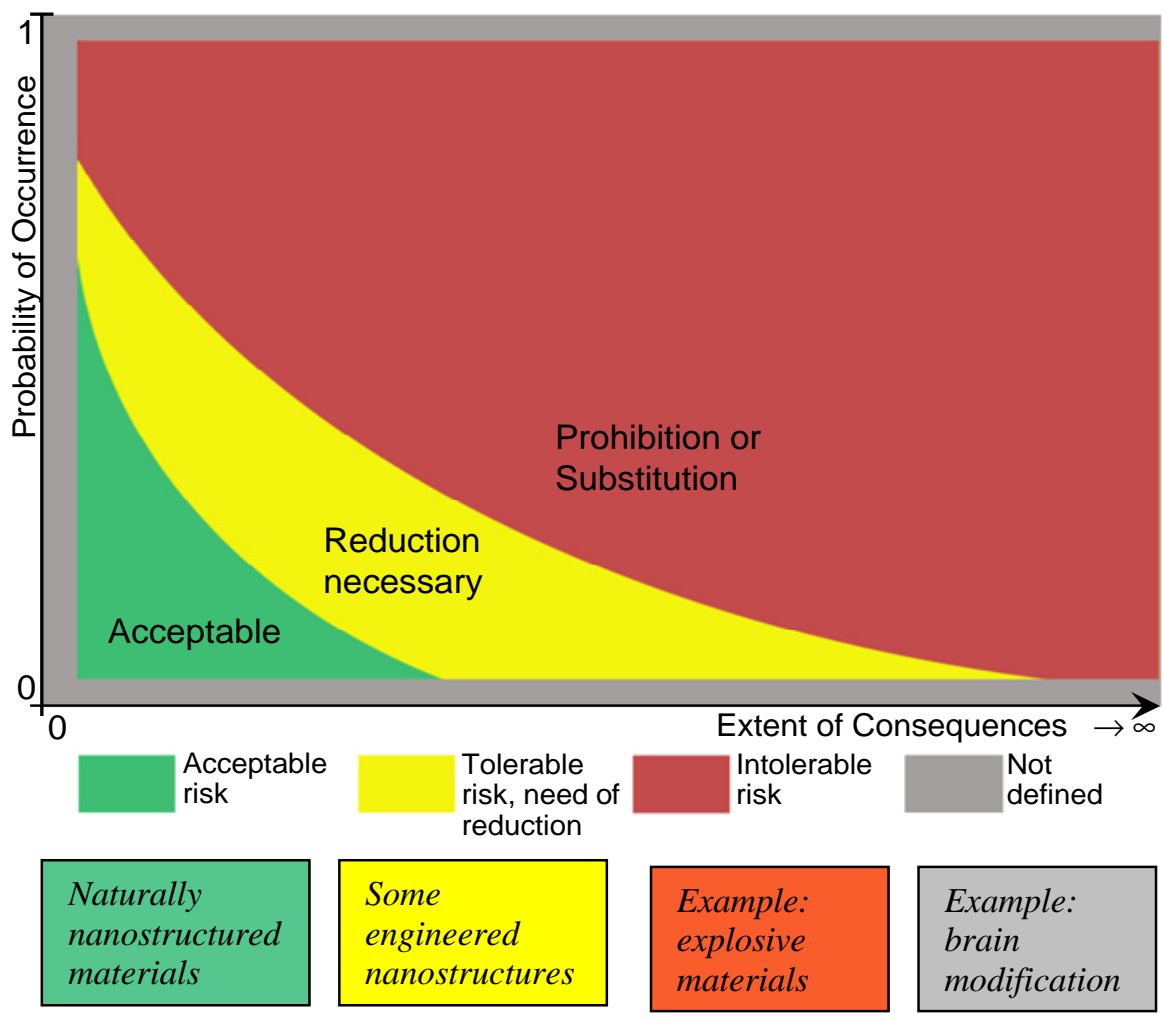

To draw the line between 'intolerable' and 'tolerable' as well as 'tolerable' and 'acceptable' is one of the most difficult tasks of risk governance. The UK Health and Safety Executive have developed a procedure for chemical risks based on risk-risk comparisons (Löfstedt 1997). Some Swiss cantons such as Basle County experimented with Round Tables as a means to reach consensus on drawing the two lines, whereby participants in the Round Table represented industry, administrators, county officials, environmentalists, and neighbourhood groups (RISKO 2000). Irrespective of the selected means to support this task, the judgement on acceptability or tolerability is contingent on making use of a variety of different knowledge sources. One needs to include the risk estimates derived from the risk assessment stage, and additional assessment data from the concern assessment. Both frames need to be represented at this stage.

Arriving at a balanced judgment means that nanotechnology will deliver sustainable added value for society, economy and industry only if it is possible to control and manage the unintended impact and risks in the sense of a societally accepted balance. It is not sufficient to include the 'physical-risk' approach, although undoubtedly important, because it addresses only part of what is at stake within culturally plural, morally concerned and educated societies (AEBC 2001; Grove-White et al. 2000).

\section{g. Risk Management}

The task of managing risks once the judgment on tolerability or acceptability has been made can be described in terms of classic decision theory, i.e. in the following steps (Morgan 1990; Keeney 1992; Hammond et al. 1999):

- Identification and generation of risk management options: Generic risk management options include risk avoidance, risk prevention, risk reduction, risk transfer and - also an option to take 
into account - self retention. Risk management by means of risk reduction can be accomplished by many different means, including the reduction of pollution at source via environmentally benign manufacturing and measures for cleaning polluted areas. Among the potential technical options, protection technology and personal protective equipment may be used for protecting oneself against nanoparticles in the air. It is, for example, assumed that the traditional aerosol control measures should work for nanoparticles if the collection devices used match the size of the particles. It should be stressed, however, that filter effectiveness for particles smaller than $15 \mathrm{~nm}$ is still uncertain. Traditional respiratory protection should also work for particles over $15 \mathrm{~nm}$; however, it is very critical that the facemask fits. It is also important to note that the NPR 100 respirators have not been tested with nanoscale particulates. It is also recommended that impervious gloves and clothing be used to minimize dermal exposure.

- Assessment of risk management options with respect to predefined criteria: Each of the options will have desired and unintended consequences which relate to the risks that they are supposed to reduce. In most instances, an assessment should be done according to the following criteria:

- Effectiveness: Does the option achieve the desired effect?

- Efficiency: Does the option achieve the desired effect with the least resource consumption?

- Minimisation of external side effects: Does the option infringe on other valuable goods, benefits or services such as competitiveness, public health, environmental quality, social cohesion, etc.? Does it impair the efficiency and acceptance of the governance system itself?

- Sustainability: Does the option contribute to the overall goal of sustainability? Does it assist in sustaining vital ecological functions, economic prosperity and social cohesion?

- Fairness: Does the option burden the subjects of regulation in a fair and equitable manner?

- Political and legal implementability: Is the option compatible with legal requirements and political programmes?

- Ethical acceptability: Is the option morally acceptable?

- Public acceptance: Will the option be accepted by those individuals who are affected by it? Are there cultural preferences or symbolic connotations that have a strong influence on how the risks are perceived?

Measuring management options against these criteria may create conflicting messages and results. Many measures that prove to be effective may turn out to be inefficient or unfair to those who will be burdened. Other measures may be sustainable but not accepted by the public or important stakeholders. In addition, finding the most acceptable solution may impair or compromise the risk governance system itself. These problems are aggravated when dealing with global risks. What appears to be efficient in one country may not work at all in another country. Risk managers are therefore well advised to make use of the many excellent guidance documents on how to handle risk trade-offs and how to employ decision analytic tools for dealing with conflicting evidence and values (c.f. Viscusi 1994; Wiener 1998; van der Sluijs et al. 2003; Goodwin and Wright 2004).

- Evaluation of risk management options: Similar to risk evaluation, this step integrates the evidence on how the options perform with regard to the evaluation criteria with a value judgement about the relative weight each criterion should be assigned. Ideally, the evidence should come from experts and the relative weights from politically legitimate decision makers. In practical risk management, the evaluation of options is done in close cooperation between experts and decision makers. As pointed out later, this is the step in which direct stakeholder involvement and public participation is particularly important and is therefore best assured by making use of a variety methods (Rowe and Freyer 2000; OECD 2002).

- Selection of risk management options: Once the different options are evaluated, a decision has to be made as to which options are selected and which rejected. This decision is obvious if one or more options turn out to be dominant (relatively better on all criteria). Otherwise, trade-offs have to be made that need legitimisation (Graham and Wiener 1995). A legitimate decision can be made on the basis of formal balancing tools (such as cost-benefit or multi-criteria-decision analysis), by 
the respective decision makers (given his decision is informed by a holistic view of the problem) or in conjunction with participatory procedures.

- Implementation of risk management options: It is the task of risk management to oversee and control the implementation process. In many instances implementation is delegated, as when governments take decisions but leave their implementation to other public or private bodies or to the general public. However, the risk management team has at any rate the implicit mandate to supervise the implementation process or at least monitor its outcome.

- Monitoring of option performance: The last step refers to the systematic observation of the effects of the options once they are implemented. The monitoring system should be designed to assess intended as well as unintended consequences. Often a formal policy assessment study is issued in order to explore the consequences of a given set of risk management measures on different dimensions of what humans' value. In addition to generating feedback for the effectiveness of the options taken to reduce the risks, the monitoring phase should also provide new information on early warning signals for both new risks and old risks viewed from a new perspective. It is advisable to have the institutions performing the risk and concern assessments participate in monitoring and supervision so that their analytic skills and experience can be utilised in evaluating the performance of the selected management options.

For nanotechnology, options should be embedded in a set of scenarios particularly for frame 2 . Those scenarios could be labelled as follows:

1. "Fears were groundless" - no significant additional hazard emerges, people start to get used to products based on nanotechnology. Negative health hazards do not show up and the concerns about social and ethical issues loose ground. Public attention moves to other issues. If this scenario materialises, the normal methods of risk management such as risk-benefit balancing will be sufficient.

2. "Innocent until proven otherwise" - only way of testing is to approve release of products, then await signal symptoms. This scenario is based on a trial-and error approach. The main management tool here is monitoring and some containment in order to avoid irreversible damage.

3. "Not my generation" - effects are highly latent; problem affects future generations: nanotechnology is applied in many areas without any visible impact on health or the environment. But unintended and unexpected effects show up after a long time period. If this scenario is considered realistic, risk management tools such as containment (limiting application in space and time so that it can be withdrawn once the negative impacts become visible) and strict monitoring are most appropriate.

4. "Ends justified by means" - realisable benefits (medical, water filtration, energy conversion, food resources) can outweigh adverse effects: This scenario implies that some applications are regarded as legitimate and others not. This scenario is likely to become realistic if the second discourse on ethical and societal issues becomes a dominant theme in society. Managing agencies are then required to distinguish between different applications and conduct an extensive social benefit (or social need) and risk comparison to distinguish between legitimate and illegitimate applications.

5. "Too hot to handle" - Insurers introduce exclusions to product liability insurance policies for specific nanotechnology applications. This scenario implies that the uncertainties drive insurance companies to withdraw liability policies from the market. Potential producers will refrain from marketing products with nanotechnology because of fear of liability. Risk management institutions may change the rules of liability and work together with insurance companies to share the financial risks.

6. "Not invented here" - sceptics of the technology invoke precautionary principle or other barriers and succeed in imposing a de facto moratorium on all major applications. The result is that the respective industry moves out and only the final products may be imported into the country. This scenario will restrict the action of regulators and promoters of this technology. The only risk management option is to control imported products. 
7. "No, thanks" - consumers follow lead of anti-technology NGOs and boycott products with nanotechnology. This scenario assumes that negative communication can convince consumers to refrain from buying these products. Risk management agencies need to engage more in risk communication and trust building exercises to assure the consumer that the regulation is able to protect them.

There may be other scenarios to consider. The main point here is to acknowledge that the choice of risk management measures depends on the scenarios that are taken into consideration. Prudent risk management would include contingency plans for dealing with a whole variety of scenarios in order to be well prepared for changes in economy, society and politics.

\section{Table 1. Risk characteristics and their implications for risk management with reference to nanotechnology}

\begin{tabular}{|c|c|c|c|}
\hline $\begin{array}{l}\text { Knowledge } \\
\text { Characterisation }\end{array}$ & $\begin{array}{l}\text { Management } \\
\text { Strategy }\end{array}$ & Appropriate Instruments & $\begin{array}{l}\text { Stakeholder } \\
\text { Participation }\end{array}$ \\
\hline $\begin{array}{l}1 \text { 'Simple' risk } \\
\text { problems } \\
\frac{\text { Frame 1: Naturally }}{\text { nanostructured }} \\
\frac{\text { materials, where }}{\text { chemical composition }} \\
\text { determines properties }\end{array}$ & $\begin{array}{l}\text { Routine-based: } \\
\text { (tolerability/ac- } \\
\text { ceptability judge } \\
\text { ment) } \\
\text { (risk reduction) }\end{array}$ & $\begin{array}{ll}\text { ‡ } & \text { Applying 'traditional' decision-making } \\
- & \text { Risk-benefit analysis } \\
- & \text { Risk-risk trade-offs } \\
& \\
- & \text { Trial and error } \\
- & \text { Technical standards } \\
- & \text { Economic incentives } \\
- & \text { Education, labelling, information } \\
- & \text { Voluntary agreements }\end{array}$ & $\begin{array}{l}\text { Instrumental } \\
\text { discourse }\end{array}$ \\
\hline $\begin{array}{l}2 \begin{array}{l}\text { Component } \\
\text { complexity- } \\
\text { induced risk } \\
\text { problems }\end{array} \\
\text { Frame 1: Passive } \\
\text { nanostructures with new }\end{array}$ & $\begin{array}{l}\text { Risk-informed: } \\
\text { (risk agent and } \\
\text { causal chain) }\end{array}$ & $\begin{array}{cl}\text { \# } & \text { Characterising the available evidence } \\
- & \text { Expert consensus seeking tools: } \\
-\quad \text { Delphi or consensus conferencing } \\
\text { - Meta analysis } \\
\text { - } \quad \text { Scenario construction, etc. } \\
\text { - }\end{array}$ & $\begin{array}{l}\text { Epistemological } \\
\text { discourse }\end{array}$ \\
\hline $\begin{array}{l}\text { properties and functions } \\
\text { for same chemical } \\
\frac{\text { composition; } 1^{\text {st }}}{\text { generation of }} \\
\text { nanoproducts }\end{array}$ & $\begin{array}{l}\text { Robustness- } \\
\text { focussed: } \\
\text { (risk absorbing } \\
\text { system) }\end{array}$ & $\begin{array}{ll}\text { ₹ } & \text { Improving buffer capacity of risk target } \\
& \text { through: } \\
- & \text { Additional safety factors } \\
- & \text { Redundancy and diversity in designing } \\
& \text { safety devices } \\
- & \text { Improving coping capacity } \\
- & \text { Establishing high reliability organisations }\end{array}$ & \\
\hline \multirow[t]{2}{*}{$\begin{array}{l}3 \begin{array}{l}\text { System } \\
\text { uncertainty- } \\
\text { induced risk } \\
\text { problems }\end{array} \\
\frac{\text { Frame 2: Active }}{\text { nanostructures and }} \\
\text { nanosystems }\end{array}$} & $\begin{array}{l}\text { Precaution-based: } \\
\text { (risk agent) }\end{array}$ & $\begin{array}{l}\text { ₹ Using hazard characteristics such as } \\
\text { persistence, ubiquity etc. as proxies for risk } \\
\text { estimates } \\
\text { Tools include: } \\
-\quad \text { Containment } \\
-\quad \text { ALARA (as low as reasonably achievable) } \\
\text { and ALARP (as low as reasonably possible) } \\
\text { - } \quad \text { BACT (best available control technology), } \\
\text { etc. }\end{array}$ & $\begin{array}{l}\text { Reflective } \\
\text { discourse }\end{array}$ \\
\hline & $\begin{array}{l}\text { Resilience- } \\
\text { focussed: } \\
\text { (risk absorbing } \\
\text { system) }\end{array}$ & $\begin{array}{ll}\text { \# } & \text { Improving capability to cope with surprises } \\
- & \text { Diversity of means to accomplish desired } \\
& \text { benefits } \\
- & \text { Avoiding high vulnerability } \\
- & \text { Allowing for flexible responses } \\
- & \text { Preparedness for adaptation }\end{array}$ & \\
\hline $\begin{array}{l}4 \begin{array}{l}\text { Unknown; Higher } \\
\text { ambiguity-induced } \\
\text { risk problems }\end{array} \\
\frac{\text { Frame 2: Large }}{\frac{\text { nanosystems and }}{\text { molecular }}} \\
\underline{\text { nanosystems }}\end{array}$ & Discourse-based: & $\begin{array}{l}\text { ₹ Application of conflict resolution methods } \\
\text { for reaching consensus or tolerance for risk } \\
\text { evaluation results and management option } \\
\text { selection } \\
-\quad \text { Integration of stakeholder involvement in } \\
\text { reaching closure } \\
\text { Emphasis on communication and social } \\
\text { discourse }\end{array}$ & $\begin{array}{l}\text { Participative } \\
\text { discourse }\end{array}$ \\
\hline
\end{tabular}


Based on the distinction between simple risk, component and system complexity, uncertainty, and ambiguity it is possible to design generic strategies of risk management to be applied to classes of risks, thus simplifying the risk management process as outlined above. Table 1 provides an application of this management tool that has been described in more detail in IRGC (2005) for nanotechnology.

\section{h. Stakeholder Participation}

Although there have been various attempts in recent years to engage business and policymakers in anticipatory debates about emerging technologies - for example the 'Digital Futures' project on ecommerce (Wilsdon 2001) - methods for this type of upstream engagement are not well developed. A central aim of applying the IRGC model will be to stimulate participatory innovation in this area, and generate better platforms for stakeholder involvement.

How can stakeholder involvement be implemented? Again it is helpful to distinguish between simple, complex, high uncertainty and high ambiguity risk problems (Renn 2004b). How to deal with these different risk categories is explained in the last column of Table 1 and more specifically in Figure 7. Stakeholder participation is important for both frames 1 and 2 and there are four cases in which different forms of stakeholder involvement in nanotechnology governance should be considered:

$\ddot{y} \quad$ Simple risk problems: For making judgements about simple risk problems a sophisticated approach to involve all potentially affected parties is not necessary. Most actors would not even seek to participate since the expected results are more or less obvious. In terms of cooperative strategies, an 'instrumental discourse' among agency staff, directly affected groups (such as product or activity providers and immediately exposed individuals) as well as enforcement personnel is advisable. One should be aware, however, that often risks that appear simple turn out to be more complex, uncertain or ambiguous as originally assessed. It is therefore essential to revisit these risks regularly and monitor the outcomes carefully.

$\ddot{y} \quad$ Complex risk problems associated with components: The proper handling of complexity in risk appraisal and risk management requires transparency over the subjective judgements and the inclusion of knowledge elements that have shaped the parameters on both sides of the costbenefit equation. In nanotechnology, complexity often refers to each component while the whole system itself can be well defined. Resolving complexity necessitates a discursive procedure during the appraisal phase with a direct link to the tolerability and acceptability judgement and risk management. Input for handling complexity could be provided by an 'epistemological discourse' aimed at finding the best estimates for characterising the risks under consideration. This discourse should be inspired by different science camps and the participation of experts and knowledge carriers. They may come from academia, government, industry or civil society but their legitimacy to participate is by bringing new or additional knowledge to the negotiating table. The goal is to resolve cognitive conflicts. Exercises such as Delphi, Group Delphi and consensus workshops would be most advisable to serve the goals of an epistemological discourse (Webler et al. 1991; Gregory et al. 2001).

$\ddot{y} \quad$ Risk problems due to high unresolved system uncertainty: Characterising risks, evaluating risks and designing options for risk reduction pose special challenges in situations of high uncertainty about the risk estimates. How can one judge the severity of a situation when the potential damage and its probability are unknown or highly uncertain? In this dilemma, risk managers are well advised to include the main stakeholders in the evaluation process and ask them to find a consensus on the extra margin of safety in which they would be willing to invest in exchange for avoiding potentially catastrophic consequences. This type of deliberation called 'reflective discourse' relies on a collective reflection about balancing the possibilities for over- and underprotection. If too much protection is sought, innovations may be prevented or stalled; if we go for too little protection, society may experience unpleasant surprises. The classic question of 'how safe is safe enough' is replaced by the question of 'how much uncertainty and ignorance are the main actors willing to accept in exchange for some given benefit'. It is recommended that policy makers, representatives of major stakeholder groups, and scientists take part in this type of discourse. The reflective discourse can take different forms: round tables, open space forums, negotiated rule-making exercises, mediation or mixed advisory committees including scientists and other stakeholders (Amy 1983; Perrit 1986; Rowe and Frewer 2000). 
$\ddot{y} \quad$ Risk problems relating to high ambiguity due to unknown future developments and differences in value judgements: If major ambiguities are associated with a risk problem, it is not enough to demonstrate that risk regulators are open to public concerns and address the issues that many people wish them to take care of. In these cases the process of risk evaluation needs to be open to public input and new forms of deliberation. This starts with revisiting the question of proper framing. Is the issue really a risk problem or is it in fact an issue of lifestyle and future vision? The aim is to find consensus on the dimensions of ambiguity that need to be addressed in comparing risks and benefits and balancing the pros and cons. High ambiguities require the most inclusive strategy for participation since not only directly affected groups but also those indirectly affected have something to contribute to this debate. Resolving ambiguities in risk debates requires a 'participative discourse', a platform where competing arguments, beliefs and values are openly discussed. The opportunity for resolving these conflicting expectations lies in the process of identifying common values, defining options that allow people to live their own vision of a 'good life' without compromising the vision of others, to find equitable and just distribution rules when it comes to common resources and to activate institutional means for reaching common welfare so all can reap the collective benefits instead of a few (coping with the classic commoners' dilemma). Available sets of deliberative processes include citizen panels, citizen juries, consensus conferences, ombudspersons, citizen advisory commissions, and similar participatory instruments (Dienel 1989; Fiorino 1990; Durant and Joss 1995; Armour 1995; Applegate 1998).

Categorising risks according to the quality and nature of available information on risk may, of course, be contested among the stakeholders. Who decides whether a risk issue can be categorised as simple, complex, uncertain or ambiguous? It seems prudent to have a screening board perform this challenging task. This board should consist of members of the risk and concern assessment team, of risk managers and key stakeholders (such as industry, NGOs and representatives of related regulatory or governmental agencies). The type of discourse required for this task is called design discourse. It is aimed at selecting the appropriate risk and concern assessment policy, defining priorities in handling risks, organising the appropriate involvement procedures and specifying the conditions under which the further steps of the risk handling process will be conducted. Figure 7 provides an overview of the different requirements for participation and stakeholder involvement for the four classes of risk problems and the design discourse.

\section{i. Risk Communication}

Risk communication is needed throughout the whole risk handling chain, from the framing of the issue to the monitoring of risk management impacts. In the risk governance framework for nanotechnology risk communication is equally important in all four generations of development and within both frame 1 and frame 2. Communication has to be a means to ensure that (Lundgreen 1994; OECD 2002):

$\ddot{y} \quad$ those who are central to risk framing, risk and concern assessment or risk management understand what is happening, how they are to be involved, and, where appropriate, what their responsibilities are, and,

$\ddot{y} \quad$ others outside the immediate risk appraisal or risk management process are informed and engaged.

The first task of risk communication, i.e. facilitating an exchange of information among risk professionals, has often been underestimated in the literature. A close communication link between risk/concern assessors and risk managers, particularly in the phases of pre-assessment and tolerability/acceptability judgement, is crucial for improving overall governance. Similarly, co-operation among natural and social scientists, close teamwork between legal and technical staff and continuous communication between policy makers and scientists are all important prerequisites for enhancing risk management performance. This is particularly important for the initial screening phase where the allocation of risks is performed.

The second task, that of communicating risk appropriately to the outside world, is also a very challenging endeavour. Many representatives of stakeholder groups and, particularly, members of the affected and non-affected public are often unfamiliar with the approaches used to assess and manage risks and/or pursue a specific agenda, trying to achieve extensive consideration of their own viewpoints. They face difficulties when asked to differentiate between the potentially harmful properties 
of a substance (hazards) and the risk estimates that depend on both the properties of the substance, the exposure to humans, and the scenario of its uses (Morgan et al. 2002).

Figure 7. The risk management escalator and stakeholder involvement (from simple via complex and uncertain to ambiguous phenomena) with reference to nanotechnology

\begin{tabular}{|c|c|c|c|}
\hline \multirow[t]{6}{*}{$\begin{array}{l}\text { Naturally } \\
\text { nanostructured } \\
\text { materials }\end{array}$} & $\begin{array}{l}\text { Engineered } \\
\text { nanostructured } \\
\text { materials }\end{array}$ & $\begin{array}{l}\text { Active } \\
\text { nanostructures } \\
\text { and systems }\end{array}$ & $\begin{array}{l}\text { Large and } \\
\text { molecular } \\
\text { nanosystems }\end{array}$ \\
\hline & & \multirow{2}{*}{$\begin{array}{l}\text { Risk Balancing } \\
\text { Necessary } \\
+ \text { Probabilistic } \\
\text { Risk Modelling }\end{array}$} & $\begin{array}{l}\text { Risk Trade-off } \\
\text { Analysis \& Delib- } \\
\text { eration necessary } \\
\text { +Risk Balancing } \\
\text { +Probabilistic } \\
\text { Risk Modelling }\end{array}$ \\
\hline & & & \multirow{3}{*}{$\begin{array}{l}\text { Remedy } \\
\ddot{y} \text { Cognitive } \\
\ddot{y} \text { Evaluative } \\
\ddot{y} \text { Normative }\end{array}$} \\
\hline & & Remedy & \\
\hline & $\begin{array}{l}\text { Probabilistic Risk } \\
\text { Modelling }\end{array}$ & $\begin{array}{l}\ddot{y} \text { Cognitive } \\
\ddot{y} \text { Evaluative }\end{array}$ & \\
\hline & Remedy & Type of Conflict & Type of Conflict \\
\hline $\begin{array}{l}\text { Statistical Risk } \\
\text { Analysis }\end{array}$ & Cognitive & \multirow{3}{*}{$\begin{array}{l}\ddot{y} \text { Agency Staff } \\
\text { ÿ External Experts } \\
\ddot{y} \text { Stakeholders } \\
\text { - Industry } \\
\text { - Directly affected } \\
\text { groups }\end{array}$} & \multirow{3}{*}{$\begin{array}{l}\text { ÿ Agency Staff } \\
\text { ÿ External Experts } \\
\text { ÿ Stakeholders } \\
\text { - Industry } \\
\text { - Directly affected } \\
\text { groups } \\
\text { - General public }\end{array}$} \\
\hline Remedy & Type of Conflict & & \\
\hline $\begin{array}{l}\ddot{y} \text { Agency Staff } \\
\ddot{y} \text { Stakeholders }\end{array}$ & $\begin{array}{l}\ddot{y} \text { Agency Staff } \\
\ddot{y} \text { External Experts } \\
\text { ÿ Stakeholders } \\
\end{array}$ & & \\
\hline Actors & Actors & Actors & Actors \\
\hline Instrumental & Epistemological & Reflective & Participative \\
\hline Type of Discourse & Type of Discourse & Type of Discourse & Type of Discourse \\
\hline Simple & $\begin{array}{l}\text { Component } \\
\text { Complexity } \\
\text { induced }\end{array}$ & $\begin{array}{l}\text { System } \\
\text { uncertainty } \\
\text { induced }\end{array}$ & $\begin{array}{l}\text { Ambiguity } \\
\text { induced }\end{array}$ \\
\hline Risk Problem & Risk Problem & Risk Problem & Risk Problem \\
\hline \multicolumn{2}{|c|}{ Frame 1} & \multicolumn{2}{|c|}{ Frame 2} \\
\hline $\begin{array}{l}\text { Function: } \\
\text { Type of Discourse: } \\
\text { Participants: }\end{array}$ & \multicolumn{3}{|c|}{$\begin{array}{l}\text { Allocation of risks to one or several of the four routes } \\
\text { Design discourse } \\
\text { A team of risk and concern assessors, risk managers, stake- } \\
\text { holders and representatives of related agencies }\end{array}$} \\
\hline
\end{tabular}

\section{RECOMMENDATIONS}

\section{a. Research Recommendations}

Key research needs for the first generation of nanoproducts ("Frame 1" for nanotechnology risk debate) are: (1) Testing strategies for assessing toxicity and eco-toxicity, including pre-market testing and life-cycle assessment; (2) Best metrics for assessing particle toxicity and eco-toxicity; (3) Research into disposal, dispersion, and waste treatment of nano-engineered materials. (4) Exposure monitoring methodologies, including research into the effectiveness of current engineering controls and person protective equipment (Glove boxes, hoods, air filters, etc.); (5) Evaluate the probability and 
severity of risk for nanotechnology applications, including the benefits and the risks of not doing anything (for example, replacement of non-renewable energy sources); (6) Risk assessment methodologies; and (7) Communication and education concerning EHS and ELSI, including full disclosure and transparency.

Key research needs for the next generations of nanoproducts ("Frame 2" for nanotechnology risk debate) are: (1) Identifying the hazards and exposures using scenarios (see science and technology scenarios presented in Nano Frontiers, 2006) ; (2) Matrix for assessing the identified hazards; (3) Estimation of exposure for events with great uncertainties; (4) Identifying and assessing the major concerns of stakeholders and public interest groups; (5) Investigating the ethical and social dimensions of the expected impacts; (6) Developing appropriate methods of decision making in face of great uncertainties and ambiguities including stakeholder involvement; and (7) Developing capacity to address uncertain/unknown and highly controversial developments as part of risk governance at national and global levels. Key research needs for each of frame 1 and frame 2 are identified in Table 2.

Table 2. Key research needs for the two nanotechnology risk frames

\begin{tabular}{|l|l|l|l|}
\hline $\begin{array}{l}\text { Nanotechnology Risk } \\
\text { Debate }\end{array}$ & Hazard & Exposure & Risk \\
\hline Frame 1 & $\begin{array}{l}\text { Testing strategies for } \\
\text { assessing toxicity; } \\
\text { Best metrics for assessing } \\
\text { particle toxicity }\end{array}$ & $\begin{array}{l}\text { Exposure monitoring } \\
\text { methodologies; } \\
\text { Methods for reducing } \\
\text { exposure and protective } \\
\text { equipment }\end{array}$ & $\begin{array}{l}\text { Risk assessment } \\
\text { methodologies; } \\
\text { Communication and } \\
\text { education concerning EHS } \\
\text { and ELSI. }\end{array}$ \\
\hline Frame 2 & $\begin{array}{l}\text { Identifying the hazards } \\
\text { using scenarios; } \\
\text { Matrix for assessing the } \\
\text { identified hazards }\end{array}$ & $\begin{array}{l}\text { Estimation of exposure } \\
\text { for events with great } \\
\text { uncertainties using } \\
\text { methods such as casual } \\
\text { chain }\end{array}$ & $\begin{array}{l}\text { Communication and } \\
\text { education concerning EHS } \\
\text { and ELSI; Developing } \\
\text { capacity to address uncertain/ } \\
\text { unknown and ambiguous } \\
\text { developments. }\end{array}$ \\
\hline
\end{tabular}

\section{b. Risk Communication Recommendations}

In order to design an effective risk communication programme it is essential to take into account the two frames of nanotechnology (for the first and second-fourth generations of nanotechnology products, respectively, as defined before), and for each frame to consider the differences between the risks associated with (a) human health and biosystems on one side, and (b) physical infrastructure (surrounding of the biological systems) on the other side. Risk communication should avoid the strategic mistake of grouping all applications of nanoscale technologies under the single descriptor "nanotechnology" because this would blur the distinction between the two frames and their subcategories and runs the risk of discrediting the whole nanotechnology development if there is a singular incident or some other problems related to a specific application. The second major point is to have separate risk communication programmes for each of the two frames.

The first communication strategy (for both frames 1 and 2) should be designed to enlighten the discussion about the benefits and non-intended side effects and the means to identify and quantify those effects. Communication tools here refer to internet based documentation of scientific research, product labelling, press releases, consumer hot lines and similar activities.

The second strategy (particularly for frame 2) should be directed towards a broader debate on the desirability of special applications of nanotechnology in the light of ethical and social issues. The main message here could be that it is not nanotechnology that creates the problem but rather the use of this technology in a controversial application. It is certainly legitimate to reject special applications (such as using neurochips in the human brain for control of its functions without a medical justification) without having to oppose the technology that makes such an application technically feasible.

A third major strategy in risk communication is to provide public information on the principles and procedures used to test nanotechnology products, to assess potential health or ecological impacts and to monitor the effects, as well as to inform the public on investment policies in research, development 
and production. If people have the reassurance that public authorities take special care and attention to protect the population against unintended consequences of this new technology, they may be willing to invest some more trust than today in the capacity of society to control the risks and be aware of and responsive to remaining uncertainties.

It is notable that public engagement does not solve the problem; it only (and not inevitably) increases credibility and trust. It is not a guarantee to success with or without the support of positive factual evidence. The inclusion of media stakeholders in risk communication efforts may help to accelerate the pubic engagement efforts.

\section{c. Recommendations to deal with trans-boundary issues}

In an interdependent world, the risks faced by any individual, company, region or country depends not only on its own choices but also on those of others. Nor do these entities face one risk at a time: they need to find strategies to deal with a series of interrelated risks that are often ill-defined or outside of their control. In the context of nanotechnology, the risks faced in one country, for instance, may be affected by risk management failures in another country. For example, if due to lax risk regulation a major incident occurs in one country involving nanoparticles, this will have repercussions on the debate on nanotechnology in many other countries. In particular, in connection with the second frame, evidence that control mechanisms do not work in one place may fuel a fierce debate in other parts of the world about the acceptability of this technology in general.

The more interdependencies that exist within a particular setting (be this a set of organisational units, companies, a geographical area or a number of countries etc.) and the more that this setting's entities - or participants - decide not to invest in risk reduction, while being able to influence other entities, the less incentive each potentially affected participant will have to invest in protection. At the same time, however, each participant would have been better off had all the other participants invested in riskreducing measures. In other words, weak links may lead to suboptimal behaviour by everyone. This is particularly a problem for countries with a record of effective and precautious regulatory actions since this positive record can become worthless if a major incident occurs in another country due to regulatory oversight. Creating incentives for all countries to participate in risk governance is a key issue. This may be done by using cost benefit studies (to show that it is in their own interest), using better methods of communication, and designing insurance policies which take this into account.

The role of international organisations dealing with technical, economical and policy issues (OECD, UNIDO, ISO, ASTM and others), international industry and academic organisations (SRC International; International Electronics Manufacturing Initiative, ICON and others), and NGOs (ex: ETC Group, Greenpeace, Woodrow Wilson Center and others) need to be further explored.

For situations in which some participants are reluctant to adopt protective measures to reduce the chances of negative incidents, a solution might be found in a public-private partnership. This is particularly true if the risks to be dealt with are associated with competing interpretations (ambiguities) about their acceptability as well as with conflicts about the rigour necessary to monitor and regulate side effects. Both conditions seem to apply to nanotechnology. Quite a few countries perceive here an opportunity to gain a competitive advantage by developing nanotechnology products faster than competing nations. This is certainly a major reason for proposing international regulation and common strategies for risk management.

A way to structure a private-public partnership is to have government standards and regulations coupled with third party inspections and insurance to enforce these measures. Such a managementbased regulatory strategy will encourage the addressees of the regulation, often the corporate sector, to reduce their risks from e.g. accidents and disasters. It also shifts the locus of decision-making from the government regulatory authority to private companies which are as a result required to do their own planning as to how they will meet a set of standards or regulations (Coglianese and Lazer 2003). This, in turn, can enable companies to choose those means and measures which are most fit for purpose within their specific environment and, eventually, may lead to a superior allocation of resources compared to more top-down forms of regulation. The combination of third party inspections in conjunction with private insurance is consequently a powerful combination of public oversight and market mechanisms that can convince many companies of the advantages of implementing the necessary measures to make their products based on nanotechnology safer. 
It is critical that International Standards and best practices be communicated globally. This will require special effort by institutions to penetrate developing and developed countries in a reasonable time frame to help stakeholders understand the importance of regulatory actions and public-private cooperation to ensure that the opportunities are sought and the risks are either avoided or at least reduced. Mechanisms need to be established to maintain and communicate best practices in this respect, standards and knowledge and communicate to governments, industry, entrepreneurs, and universities as quickly as possible.

\section{d. Recommendations to Various Stakeholders}

These general recommendations need to be implemented by social actors. The days are gone when regulatory actions were the sole responsibility of governments. The complexity of the subject, the different types of agency among and between the different actors, the scope of responsibilities and accountability, the trans-boundary nature of benefits and risks as well as the delicate balances of power and interests make it inevitable that governmental, economic, scientific and civil actors cooperate for the purpose of better regulation of nanotechnology. Many of the recommendations and suggestions developed above are directed towards governments, but national governments are often unable to operate effectively on the global level. They need the cooperation of private often transnationally operating companies and civil society actors who increasingly organise themselves on the global level.

The private sector is a major player in the development and diffusion of nanotechnology. It is in the best interest of private investors to assure that minimum standards for safety and health protection are established and enforced internationally and that potential risks are investigated and assessed before actual damage occurs. The international business community is well aware that the development of nanotechnology applications depends heavily on public confidence in the ability of industry and government to control risks and on the flexibility and creativity of the business sector to deal with new information and research results about potential impacts, be they positive or negative.

Due to the lack of global governance structures in dealing with nanotechnology regulation, one of the most promising routes for private actors is the establishment of voluntary codes or rules with respect to minimum requirements for assuring safety and risk control. One major incident in a remote country can trigger international reactions that might go far beyond the actual case. Therefore it is important for internationally operating companies to make sure that all their facilities follow identical EHS-standards and requirements if actual practices may be formed according to local or regional traditions. Beyond the harmonisation of standards in multinational companies, voluntary agreements and codes for the entire industry may also help to reduce risks and sustain public trust and confidence.

One possibility to consider is the establishment of a certification system that would force all companies to adhere to specific rules when applying for this certificate. Such a system could be modelled according to the Forest Stewardship Council or similar organisational settings. Another possibility may be the establishment and enforcement of international standards (for example ISO-standards) that require companies to follow predefined rules for safety and protection of public health. Demonstrating that private industry has done what it can to protect the public and the environment is the best guarantee that the benefits of this technology will unfold and thus improve living standards as well as public confidence.

Voluntary agreements, certificates or international standards are suitable instruments for dealing with potential risks of nanotechnology applications in short term until formal norms would be established. The second frame includes concerns about social disturbance, threat to human identity and cultural values. The ambiguity associated with these endpoints of risks demands a more discursive and participatory approach and private industry should be willing and prepared to engage in such a dialogue programme. One could think of public statements about ethical implications of one's own research including the promise not to engage in certain ethically problematic areas of application (even if they are legal). Another possibility is to initiate public forums or Round Tables amongst major stakeholders and concerned groups with the objective being to explore potential social risks and design barriers to prevent them from occurring. If industry can convey the message that they take these concerns seriously, and are willing to shape and reshape their own policies in accordance with reasonable demands of precaution against such social risks, the struggle for more trust and confidence can lead to success. 
Both voluntary agreements and new forms of dialogue and public consultation are also attractive to non-governmental organisations as it is in their interest to make sure that environmental quality and public health are assured through the appropriate means. Often they also pursue secondary goals such as equity, social justice and assistance to the poor and these concerns can be integrated into the policies of voluntary agreements and public forums. The constructive processing of conflicts in suitable arenas is probably the most effective way to control the risks while still enjoying the benefits.

Table 3 lists more specific recommendations for the main societal actors in regulating nanotechnology. The list includes suggestions for private industry, academia, governments, civil society actors and international organisations. Being an international organisation, IRGC can assist private companies, social associations and NGOs to deal with both frames simultaneously. It can also provide advice on what kind of voluntary codes of conduct are needed and offer a platform for exchanging views and concerns on the issues belonging to the second frame. Risk managers and regulators should selectively focus on those aspects of the conceptual framework for risk governance of nanotechnology presented in this paper that are essential for their nanotechnology application (s).

Table 3. Recommendations to stakeholders

\begin{tabular}{|c|c|}
\hline Stakeholder & Recommendations \\
\hline Academia & 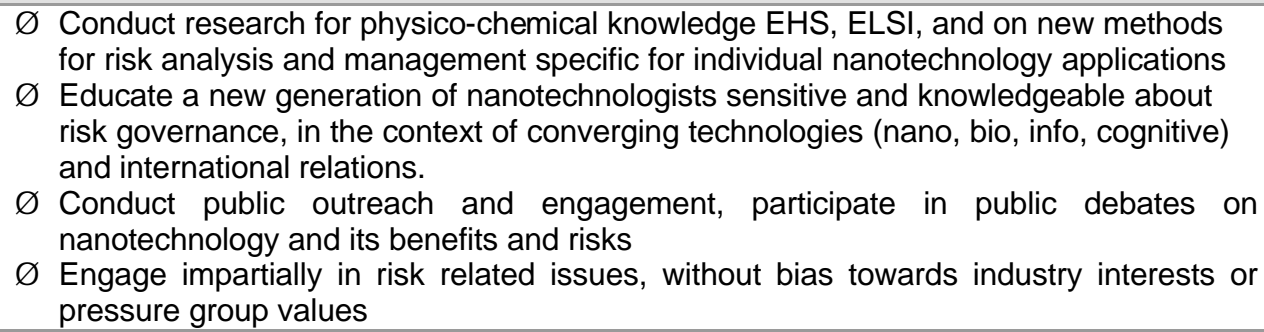 \\
\hline Industry & 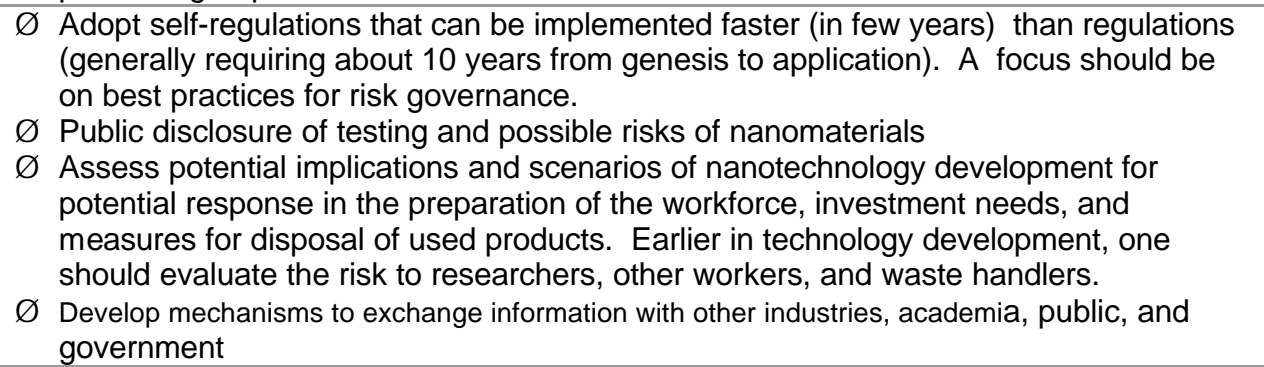 \\
\hline Government & 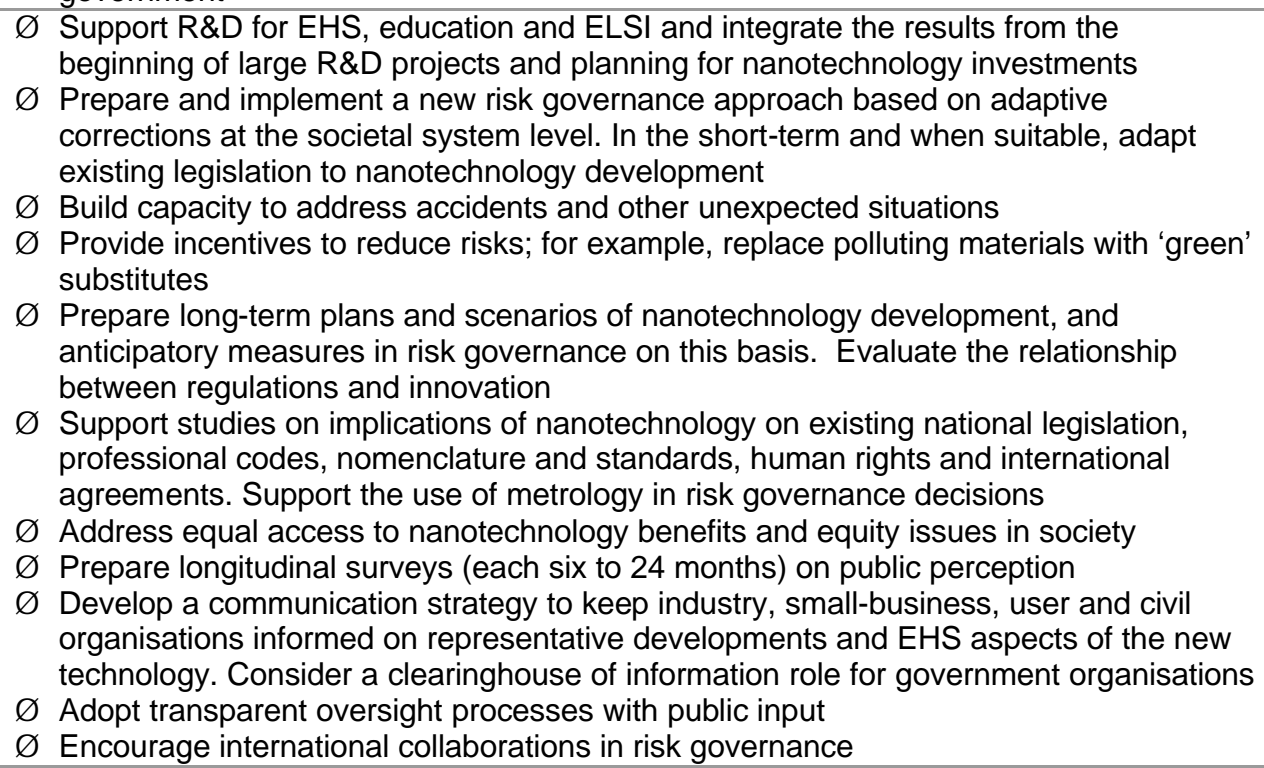 \\
\hline $\begin{array}{l}\text { User, public, } \\
\text { NGOs and civil } \\
\text { organisations }\end{array}$ & 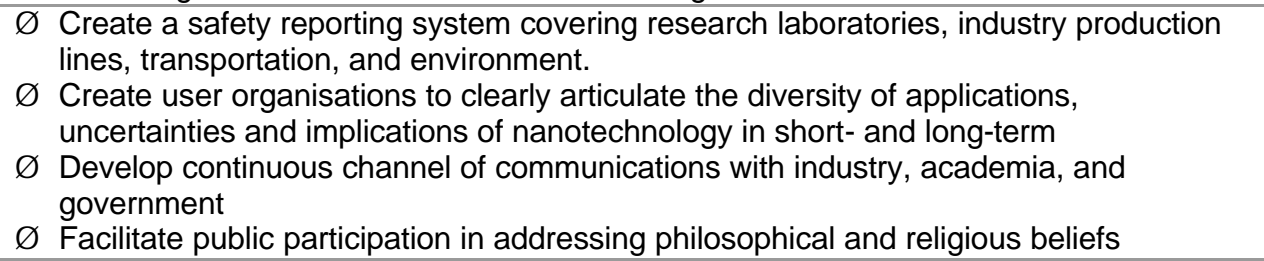 \\
\hline
\end{tabular}




\begin{tabular}{|c|c|}
\hline $\begin{array}{l}\text { International } \\
\text { organisations }\end{array}$ & $\begin{array}{ll}\text { ÿ } & \text { Communication among government and non-government organisations in various } \\
& \text { countries } \\
\ddot{y} & \text { Encourage and support coherent policies and regulatory frameworks for } \\
\text { nanotechnology } & \\
\ddot{y} & \text { Establish shared data bases for EHS/Education/ELSI results and develop programmes } \\
& \text { for periodical exchanges of information } \\
\ddot{y} & \text { Support studies on macroeconomic trends, trade implications and avoiding possible } \\
& \text { international disruptions, particularly for developing countries that do not have the } \\
& \text { capacity to fully protect their interests } \\
\ddot{y} & \text { Coordinate intellectual property issues for nanotechnology } \\
\ddot{y} & \text { Establish certification programmes for risk governance in an organisation } \\
\ddot{y} & \text { Connect risk management practices to international practices and standards (ISO) }\end{array}$ \\
\hline
\end{tabular}

\section{e. The Role of the IRGC}

This paper has aimed to develop a conceptual framework for the global governance of risks associated with those technical areas and applications of nanotechnology for which there is an apparent need for improved approaches to risk and safety issues.

Risk governance for nanotechnology is an important issue for the IRGC as it touches its main mission and relates to all the major elements of the IRGC risk governance model (see Figures 2 and 8). Given the dominance of the two frames of the nanotechnology debate (for the first and second-fourth generations of nanotechnology products, respectively), there is a real danger that the response of national risk management agencies is not sufficiently adequate to address the problems and challenges in both frames at the national and global levels and hence may lose trust and perceived competence. It is important that the risk management agencies are prepared to consider all the stages of the risk governance process and develop tools that address the challenges on each step in the process. This implies that sufficient resources are invested in risk governance and that the persons dealing with this issue are adequately trained and prepared for improving their performance. Beyond the national governments, IRGC is convinced that cooperation between governmental agencies, the private sector, civil society actors and the science communities is crucial for a governance structure that is effective, efficient and fair. It can design and inspire processes aiming at internationally agreeable standards and rules and it can promote and actively participate in dialogues on the many still intangible implications of the second to fourth application of nanotechnology.

\section{Figure 8. Risk governance overview (the IRGC core risk governance process is detailed in Figure 2)}

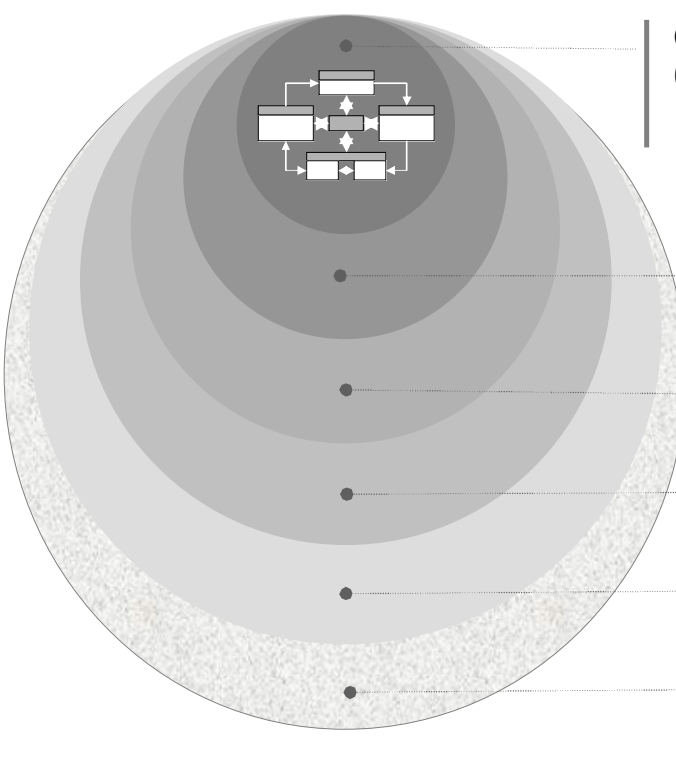

Core Risk Governance Process

(pre-assessment, risk appraisal,

tolerability/acceptability judgement,

risk management, communication)

Organisational Capacity

(assets, skills, capabilities)

\section{Actor Network}

(politicians, regulators, industry/

business, NGOs, media, public)

\section{Social Climate}

(trust in regulatory institutions, perceived authority of science civil society involvement)

\section{Political, Regulatory Culture}

(different regulatory styles)

International Context

(collaboration and competition, common challenges, leveraging) 
The IRGC could facilitate such processes. It can provide models and assistance and expertise in doing risk assessment and concern assessment. Although the IRGC has no analytic capacity to perform these assessments themselves it can help to set up the global and long-term frameworks for research plans and regulations, assist in developing or applying methods and analytical techniques, and facilitate the necessary involvement and communication process. Furthermore it can provide checklists for an effective and efficient risk management plan and help to detect weak links in the system. Most important is the role of the IRGC to initiate and promote international strategies for dealing with nanotechnology risks and making suggestions for effective public-private partnerships. At this point, IRGC is committed to perform the following concrete tasks:

$\ddot{y} \quad$ Risk assessment. IRGC intends to carry out a risk assessment for selected application areas which have been identified as important by various stakeholders:

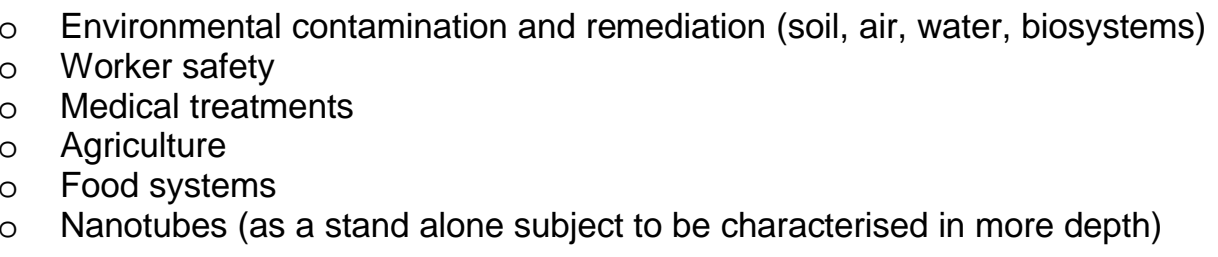

$\ddot{y}$ Concern assessment. Of special interest in this context is the concern assessment phase, a novel element that the IRGC has suggested as a supplement to the classic risk assessment. Risk managers need to be informed about the structure and strength of the various frames that individuals and groups associate with nanotechnology. For this purpose, IRGC have conducted global surveys with the leading individuals of government, industry, NGOs, international organisations and others. In addition interviews with civil society groups such as consumer unions, environmental groups, religious communities, and others need to be conducted and interpreted. If simultaneously done in many countries, one can compare insights from all of the international studies and conduct a systematic evaluation in terms of intensity of concerns, types of concerns and willingness to act. Such an analysis is not only a means for identifying potential barriers and obstacles to the diffusion of nanotechnology it is also an important input for the construction of scenarios and for the identification of potential opportunities based on revealed preferences of the main actors. In addition, risk managers being able to understand the frames that govern the perception process would be better equipped to design appropriate risk management and risk communication strategies.

$\ddot{y} \quad$ Risk management. As a primary outcome of these assessments IRGC will contribute towards developing models for risk governance policies, dealing with disagreements, responding to changes in time, and overall international interactions. These models will be debated and agreed amongst key stakeholders at an international conference resulting in a final set of recommendations for risk governance of frame 1 and frame 2. Activities for increasing public awareness of nanotechnology and participation in making investment decisions will also be evaluated in this context as a method for reducing risk.

ÿ Risk communication. IRCG will develop a white paper on nanotechnology risk governance and surveys of key stakeholders. The reports will be disseminated to key potential users and posted on the IRGC website. In addition, IRGC will facilitate the production of risk communication material by different agencies and organisations. It will also provide a platform for different actors in this debate to exchange ideas, concerns, and insights with the goal to reach consensus on the appropriate regulatory actions, possible private-public partnerships and risk education and communication needs. A clearinghouse role for collecting and disseminating important information on risk governance and use of databases is considered.

\section{f. A Potential Future Role for International Bodies}

Stakeholders can contribute to framing the issues related to the risks of nanotechnology by adopting a proactive approach. For example, one should focus on how one can engineer safe nanostructures and nanosystems instead of observing that some nanostructures are not safe. In another example, collaboration should take place among various specialised organisations (such as the International Dialogue (2004) and the National Institute for Occupational Science and Health (US)) to create and 
maintain data bases for knowledge on toxicity for nanomaterials, regulations, R\&D needs and investment needs.

National or international exercises for constructing scenarios that appear relevant to the context of the diffusion of nanotechnology and the likely social reactions to it should also take place. The scenarios suggested in this report may serve as default options for designing more specific scenarios that relate to the specific situation and the contextual conditions of the countries selected for the analysis. Academic researchers, developers, potential users and important other actors should be actively involved in this scenario building exercise in order to get an adequate representation of societal forces that ultimately shape the future of nanotechnology.

Last, but not least a targeted and effective communication programme is necessary which includes suggestions for a special educational initiative in the context of the worldwide activities to enhance public understanding of sciences and humanities. One could imagine that an international expert organisation may help agencies, NGOs or companies to design specific communication and educational material such as Internet presentations, brochures, press releases, consumer product labels and others. One should be aware, however, that those means only affect the first frame of the debate. For meeting the challenges of the second frame, other communication means are needed such as an open forum on the use and abuse of nanotechnology for medical, military or other controversial purposes. In addition, citizen panels or joint action committees (including consumer associations, unions, employers, etc,) could be convened to draft recommendation for regulatory provisions that would inhibit the potential misuse of nanotechnology. All these activities would be able to preserve or even restore trust in the risk managing agencies.

By considering the particularities of nanotechnology as an emerging technology, the proposed conceptual framework and guidelines on risk governance provide a step forward in assisting risk management agencies as well as private companies to integrate scientific assessments and concern assessments into one appraisal process and to select the appropriate risk management and stakeholder involvement strategies.

\section{ACKNOWLEDGEMENTS}

The report was prepared for IRGC and the opinions expressed here are those of the authors and do not necessarily represent those of their organisations. The reviews provided by Dr. Gerd Bachmann (VDI, Germany), Dr. Michael Garner (Intel), Tim Mealey (Meridian Institute, U.S.), Dr. David Rejeski (WWSC, U.S.) and Prof. Joyce Tait (U.K.) are acknowledged and their input is included in the document.

\section{REFERENCES}

Agriculture and Environment Biotechnology Commission (AEBC: 2001) "Crops on Trial", AEBC, London.

Altmann, J. (2006) "Military Nanotechnology: Potential Applications and Preventive Arms Control", ISBN 0-415-37102-3, November 2005, Routledge, London/New York. http://www.ep3.rub.de/bvp/milntpac.html.

Alyaudtin, R. N., Reichel, A. et al (2001) "Interaction of poly (butylcyanoacrylate) nanoparticles with the blood-brain barrier in vivo and in vitro", Journal of Drug Targeting, 9(3), pp. 209-213.

Amy, D. J. (1983) "Environmental Mediation: An Alternative Approach to Policy Stalemates," Policy Sciences, 15, pp. 345-365.

Applegate, J. (1998) "Beyond the Usual Suspects: The Use of Citizens Advisory Boards in Environmental Decision Making," Indiana Law Journal, 73, p. 903. 
Armour, A. (1995) "The Citizen's Jury Model of Public Participation," in: O. Renn, T. Webler and P. Wiedemann (eds.), Fairness and Competence in Citizen Participation: Evaluating New Models for Environmental Discourse, Springer (formerly Kluwer): Dordrecht and Boston, pp. 175-188.

Arnall, A. (2003) "Future technologies, Today's choices: Nanotechnology, artificial intelligence and robotics; a technical, political and institutional map of emerging technologies" (report for the Greenpeace Environmental Trust), Department of Environmental Science and Technology, University of London.

Bainbridge, W.S. (2002) "Public Attitudes toward Nanotechnology", Journal of Nanoparticle Research, 4(6), pp. 561-570.

Baumgartner, W., Jäckli, B., Schmithüsen, B. and Weber, F. (2003) "Nanotechnologie in der Medizin" Studie des Schweizerischen Zentrums für Technologiefolgen-Abschätzung, TA 47/2003.

Bennat, C. and Müller-Goymann, C.C. (2000) "Skin penetration and stabilization of formulations containing microfine titanium dioxide as physical UV filter", in: International Journal of Cosmetic science, 22, pp. 271-283.

Better Regulation Task Force (2003) "Scientific Research: Innovation with Controls", London: Cabinet Office.

Boholm, A. (1998) "Comparative Studies of Risk Perception: A Review of Twenty Years of Research", Journal of Risk Research, 1(2), pp. 135-163.

Burke, D. (2003) "This will be like no other debate", Times Higher Education Supplement, 21 March 2003.

Cobb, M.D. and Macoubrie, J. (2004) "Public Perceptions about Nanotechnology: Risks, Benefits and Trust", Journal of Nanoparticle Research, Springer, 6(4), pp. 395-405.

Coglianese, C. and Lazer, D. (2003) "Management-based regulation: Prescribing private management to achieve public goals", Law and Society, 37, pp. 691-730.

Collaborative Board for Advancing Nanotechnology between NNI and industry (CBAN: 2006) "Joint NNI-Chl CBAN and SRC CWG5 Nanotechnology EHS Research Needs Recommendations", Washington, D.C., January 20, 2006, 18 pages.

Collins, H.M. and Evans, R. (2002) "The Third Wave of Science Studies: Studies of Expertise and Experience", Social Studies of Science, 32(2), pp. 235-296.

Colvin, V.L. (2003) "The potential environmental impact of engineered nanomaterials", Nature Biotechnology, 21(10), pp. 1166-1170.

Crichton, M. (2002) "Prey”, London: Harper Collins.

Department of Trade and Industry/Office of Science and Technology (DTI: 2002) "New Dimensions for Manufacturing: A UK Strategy for Nanotechnology", London: DTI/OST.

Dick, C.A.J., Brown, D.M. et al. (2003) "The role of free radicals in the toxic and inflammatory effects of four different ultrafine particle types" Inhalation Toxicology, 15(1), pp. 39-52.

Dienel, P.C. (1989) "Contributing to Social Decision Methodology: Citizen Reports on Technological Projects," in: C. Vlek and G. Cvetkovich (eds.) Social Decision Methodology for Technological Projects, Kluwer: Dordrecht and Boston, pp. 133-151.

Durant, J. and Joss, S. (1995) "Public Participation in Science", Science Museum: London.

EC (2004) "Converging Technologies - Shaping the Future of European Societies", Alfred Nordmann - Rapporteur, Bruxelles 
Environmental Defense (2005) "Getting Nanotechnology Right the First Time", in the National Academy of Sciences Issues in Science and Technology, summer 2005, pp. 65-71.

ETC Group (2003) “The Big Down: From Genomes to atoms”, ETC Group.

ETC Group (2005) "The Potential Impact of Nanoscale Technologies on Commodity Markets: The Implications for Commodity Dependent Developing Countries, ETC Group - South Center.

Fiorino, D. J. (1990) "Citizen Participation and Environmental Risk: A Survey of Institutional Mechanisms", Science, Technology, \& Human Values, 15(2), pp. 226-243.

Fogelberg, H. and Glimell, H. (2003) "Bringing Visibility to the Invisible", STS Research Reports, 6. http://www.sts.gu.se/publications/STS_report_6.pdf.

Funtowicz, S. and Ravetz, J. (1993) “Science for the post-normal age”, Futures, 25(7), pp. 739-755.

Garud, R., and Ahlstrom, D. (1997) "Technology assessment: a socio-cognitive perspective", Journal of Engineering and Technology Management, 14, pp.25-48.

Gaskell, G., Allum, N., Wagner, W., Kronberger, N., Torgersen, H., Hampel, J. and Bardes, J. (2004) "GM Foods and the Misperception of Risk Perception", Risk Analysis, 24(1), pp. 185-194.

Geiser, M., Rothen-Rutishauser, B., Kapp, N., Schurch, S., Kreyling, W., Schultz, H., Semmler, M., Hof, V., Heyder J., and Gehr, P. (2005) "Ultrafine Particles Cross Cellular Membranes by Nonphagocytic Mechanisms in Lungs and in Cultured Cells", Environmental Health Perspectives, 113(11), pp. 1555-1560.

Goodwin, P. and Wright, G. (2004) "Decision Analysis for Management Judgement”, Wiley: London.

Graham, J.D. and Wiener, J.B. (1995) "Risk vs. Risk", Harvard University Press: Cambridge.

Goorden, L. (2003) "Finding a balance between Technological Innovation and Deliberation: Lessons from Belgian Public Forums on Biotechnology", paper prepared for the session New Forms of Citizen Participation in Technology Policy: European perspectives at the Annual Meeting of the American Political Science Association, Philadelphia, USA, August 28-31, 2003.

Gregory, R., McDaniels, T., and Fields, D. (2001) "Decision Aiding, Not Dispute Resolution: A New Perspective for Environmental Negotiation”, Journal of Policy Analysis and Management, 20(3), pp. 415-432.

Grin, J. et al. (1997) "Interactive Technology Assessment: een eerste gids voor wie het wagen wil", Rathenau Instituut: Den Haag.

Grin, J. and Grunwald, A. (eds.) (1999) "Vision Assessment: Shaping Technology in 21st Century Society. Towards a Repertoire for Technology Assessment”, Springer: Berlin.

Grin, J. (2004) "De politiek van omwenteling met beleid", Rede, vrijdag 16 april 2004, Universiteit Amsterdam.

Grove-White, R., Macnaghten, P. and Wynne, B. (2000) "Wising up: The public and new technology", CSEC: Lancaster.

Hammond, J., Keeney, R. and Raiffa, H. (1999) "Smart Choices: A Practical Guide to Making Better Decisions", Harvard Business School Press: Cambridge.

Hampel, J., Klinke, A. and Renn, O. (2000) "Beyond 'Red' Hope and 'Green' Distrust, Public Perception of Genetic Engineering in Germany", Politeia, 16(60), pp. 68-82.

Hanssen, L. and van Est, R. (2004) "De dubbele boodschap van nanotechnologie. Een onderzoek naar opkomende publiekspercepties", Rathenau Instituut: Den Haag. 
Health and Safety Executive (eds.) (HSE: 2004a) "Health effects of particles produced for nanotechnologies", EH75/6 December 2004, Health and Safety Executive: Great Britain.

Hett, A. (2004) "Nanotechnology: Small matter, many unknowns", Risk Perception Series, Swiss Reinsurance Company, Zurich, Switzerland.

Hoet, P.H.M., Brüske-Hohlfeld, I. and Salata, O.V. (2004) "Nanoscale particles - known and unknown health risks", Journal of Nanobiotechnology, 2(12), DOI: 10.1186/1477-3155-2-12. http://www.jnanobiotechnology.com/content/2/1/12

Huang, Z., H. Chen, Z.K. and Roco, M.C. (2004) "Longitudinal Patent Analysis for Nanoscale Science and Engineering in 2003: Country, Institution and Technology Field Analysis based on USPTO patent database", Journal of Nanoparticle Research, 6(4), pp. 325-354.

International Risk Governance Council (IRGC: 2005) "White Paper on Risk Governance", IRGC: Geneva.

Jani, P., Halbert, G.W. et al. (1990) "Nanoparticle uptake by the rat gastrointestinal mucosa: Quantification and particle size dependency", in Journal of pharmacy and pharmacology, 42(12), pp. 821-826.

Johansson, M. (2003) "Plenty of room at the bottom: Towards an anthropology of nanoscience", Anthropology Today, 19(6), pp. 3-6.

Jopp, K. (2003) "Nanotechnologie - Aufbruch ins Reich der Zwerge”, Gabler: Wiesbaden.

Joy, B. (2000) "Why the future doesn't need us", Wired, 8(4), April 2004, pp. 1-11. http://www.wired.com/wired/archive/8.04/joy.html.

Keeney, R. (1992) "Value-Focused Thinking: A Path to Creative Decision Making", Harvard University Press: Cambridge.

Kom-passion Group - Germany, (2005), http://www.kommpassion.de/index.php?id=648\&no_cache=1\&sword_list[]=nanotechnologie

Kreuter, J. (2003) "Periodical administration of nanoparticles", Advanced Drug Delivery Review, 7(1), pp. 71-86.

Li, X. Y., Brown, D. et al. (1999) "Short term inflammatory response following intratracheal instillation of fine and ultrafine carbon black in rats", Inhalation Toxicology, 11(8), pp. 709-731.

Löfstedt, R.E. (1997) "Risk Evaluation in the United Kingdom: Legal Requirements, Conceptual Foundations, and Practical Experiences with Special Emphasis on Energy Systems", Working Paper No. 92, Akademie für Technikfolgenabschätzung: Stuttgart.

Lundgren, R.E. (1994) "Risk Communication: A Handbook for Communicating Environmental, Safety, and Health Risks", Battelle Press: Columbus/Ohio 1994.

Lyall, C. and Tait, J. (2005) "Shifting Policy Debates and the Implications for Governance", in Lyall, C. and Tait, J. (eds.), in New Modes of Governance, Developing an Integrated Approach to Science, Technology, Risk and the Environment, Ashgate Publishing Ltd.: Aldershot, pp. 1-17.

Macoubrie, J. (2005) "Informed Public Perception on Nanotechnology and Trust in Government", Project on Emerging Nanotechnologies, Woodrow Wilson International Center for Scholars: New York.

Maynard, A.D. and Kuempel, E.D. (2005) "Airborne Nanostructured Particles and Occupational Health“, J. of Nanoparticle Research, 7(6), 587-614.

Meridian Institute (2004) "Summary of the International Dialogue for Responsible R\&D of Nanotechnology", sponsored by the National Science Foundation: Alexandria, Virginia, U.S.A. 
(www.nsf.gov/home/crssprgm/nano/dialog.htm)

Morgan, K. (2005) "Development of a Preliminary Framework for Informing the Risk Analysis and Risk Management of Nanoparticles", Risk Analysis, 25 (6), pp. 1621-1635.

Morgan, M.G. (1990) "Choosing and Managing Technology-Induced Risk," in: T.S. Glickman and M. Gough (eds.) Readings in Risk, Resources for the Future: Washington, pp. 17-28.

Morgan, M.G., Fischhoff, B., Bostrom, A. and Atman, C.J. (2002) "Risk Communication: A Mental Models Approach”, Cambridge University Press: Boston and New York.

Morgan, M.G. and Henrion, M. (1990) "Uncertainty: A Guide to Dealing with Uncertainty in Quantitative Risk and Policy Analysis", Cambridge University Press: Cambridge.

Nano Frontiers (2006) "Frontiers in Nanoscience and Nanotechnology", report from workshop held on Feb. 9-10, 2006, sponsored by National Institutes of Health, National Science Foundation and Woodrow Wilson Center for Scholars, Washington, D.C., U.S.

National Toxicology Program (2005) various documents published on the website: http://ntpserver.niehs.nih.gov/index.cfm.

Nature (2003) "Nanotech is not so scary", Nature, 421(6921), pp. 299.

Oberdörster, G; Sharp, Z., Atudorei V., Elder, A., Gelein, R., Kreyling, W. and Cox, C. (2002) "Extrapulmonary translocation of ultrafine carbon particles following whole-body inhalation exposure of rats", Journal of Toxicology and Environmental Health, 65(20), pp. 1531-1543.

Oberdörster, G., Sharp, Z., Atudorei, V., Elder, A., Gelein, R., and Kreyling, W. (2004) "Translocation of inhaled ultrafine particles to the brain", Inhalation Toxicology, 16(6-7), June 2004, pp.437445.

Oberdörster, G., Oberdörster, E., and Oberdörster, J. (2005) "Nanotoxicology: An emerging discipline evolving from studies of ultrafine particles", Environmental Health Perspectives, 113(7), July 2005, pp. 823-839.

OECD (2002) "Guidance Document on Risk Communication for Chemical Risk Management”, OECD: Paris.

Oliver, J. (2003) “Charles: 'Grey Goo' Threat to the World”, The Mail on Sunday, 27 April, 2003.

Paschen, H. Coenen, C., Fleischer, T., Grünwald, R., Oertel, D., Revermann, C. (2003) "Nanotechnologie. Forschung, Entwicklung, Anwendung. Bericht des Büros für Technikfolgenabschätzung des deutschen Bundestages", Springer: Berlin.

Perritt, H. H. (1986) "Negotiated Rulemaking in Practice", Journal of Policy Analysis and Management, 5 (Spring 1986), pp. 482-95.

Porritt, J. (2003) "Big questions now loom over the world's smallest technologies. And the sooner we get to grips with them, the better it will be for all of us", The Mail on Sunday, 27 April, 2003.

Pritchard, D.K. (2004) "Literature review - explosion hazards associated with nanopowders", Health and Safety Executive, London.

http://www.hse.gov.uk/research/hsl_pdf/2004/hsl04-12.pdf.

Ravetz, J. (1999) "What is Post-Normal Science?" Futures, 31(7), pp. 647-653.

Rejeski, D. (2005) Keynote speech at the EPA Grantees Conference, Washington, D.C., October 2005

Renn, O. (2004a) "Perception of Risks," The Geneva Papers on Risk and Insurance, 29(1), pp. 102114. 
Renn, O. (2004b) "The Challenge of Integrating Deliberation and Expertise: Participation and Discourse in Risk Management," in: T. L. MacDaniels and M.J. Small (eds.): Risk Analysis and Society An Interdisciplinary Characterization of the Field, Cambridge University Press: Cambridge 2004, pp. 289-366.

Rip, A. (2002) "Co-evolution of Science, Technology and Society", expert review for the Bundesministerium Bildung und Forschung's Förderinitiatieve, Politik Wissenschaft und Gesellschaft, as managed by the Berlin-Brandenburgische Akademie der Wissenschaften, Twente University, Enschede.

Rip, A. (2004a) "Constructive Technology Assessment of Nanotechnology", 15 April 2004, University of Twente.

Rip, A. (2004b) "Articulating Images, Attitudes and Views of Nanotechnology: Enactors and comparative Selectors", 14 April 2004, University of Twente.

RISKO (2000) "Mitteilungen für Kommission für Risikobewertung des Kantons Basel-Stadt: Seit 10 Jahren beurteilt die RISKO die Tragbarkeit von Risiken“, Bulletin, 3, June 2000, pp. 2-3.

Robichaud, C.O., Tanzil, D., Weilenmann, U. And Wiesner, M.R. (2005) "Relative Risk Analysis of Several Manufactured Nanomaterials: An Insurance Industry Context", Environment, Science, and Technology, 39(22), pp. 8985-8994.

Roco, M.C. (2001) "International Strategy for Nanotechnology Research", Journal of Nanoparticle Research, 3(5-6), pp. 353-360.

Roco, M.C. (2003) "Broader Societal Issues of Nanotechnology", Journal of Nanoparticle Research, 5(3-4), pp. 181-189.

Roco, M.C. (2004a) "Nanoscale Science and Engineering: Unifying and Transforming Tools", AIChE Journal, 50(5), pp. 890-897.

Roco, M.C. (2004b) "Environmentally Responsible Development of Nanotechnology", in Karn and Zhang (eds.), Special issue of Environmental Science and Technology, American Chemical Society.

http://pubs.acs.org/cgi-bin/sample.cgi/esthag-a/2005/39/i05/pdf/030105feature_roco.pdf

Roco, M.C. (2005a) "International Perspective on Government Nanotechnology Funding in 2005", Journal of Nanoparticle Research, 7(6), pp. 707-712.

Roco, M.C. (2005b) "The emergence and policy implications of converging new technologies integrated from the nanoscale", Journal of Nanoparticle Research, 7(2-3), pp. 129-143.

Roco, M.C, and Bainbridge, W.S. (eds.) (2001) "Societal Implications of Nanoscience and Nanotechnology", NSET Workshop report, March 2001, Virginia; based on National Science Foundation (NSF) workshop in September 2000, Springer (formerly Kluwer): Dordrecht.

Roco, M.C. and Bainbridge, W.S. (eds) (2003) "Converging Technologies for Improving Human Performance", NSF-DOC Report, June 2002, Virginia; based on National Science Foundation (NSF) workshop in December 2001, Springer (formerly Kluwer): Dordrecht.

Roco, M.C., and Bainbridge, W.S. (eds.) (2005) "Societal Implications of Nanoscience and Nanotechnology - Improving Benefits to Humanity" (NSET and National Science Foundation) Arlington, Virginia; on the website www.nano.gov (also published by Springer, 2005).

Roco, M.C. and Litten, E., (2005) "Survey on Nanotechnology Governance: (I) The Role of Government", IRGC, Geneva.

Roco, M.C., and Tomellini, R. (ed.) (2002) "Nanotechnology: Revolutionary Opportunities and Societal Implications", 3rd joint EC-NSF workshop on Nanotechnology, Lecce (Italy), 31 Jan-1 Feb. 2002, Office for Official Publications of the European Communities, Luxembourg. 
Rowe, G., and L.J. Frewer (2000) "Public participation methods: A framework for evaluation. Science, Technology, \& Human Values" 25(1), pp. 3-29.

Roxburgh, C. (2003) "Hidden Flaws in Strategy", McKinsey Quarterly, No. 2.

Service R. F. (2003) "News focus: Nanomaterials show signs of toxicity", Science, 300, April 2003, p. 243.

Siegel, R.W., Hu, E., and Roco, M.C., eds. (1999) "Nanostructure Science and Technology" Springer (former Kluwer Academic Publishers): Dordrecht, Netherlands (also available at http://www.wtec.org/loyola/nano/).

Slovic, P. (1992) "Perception of Risk: Reflections on the Psychometric Paradigm", in Krimsky, S., Golding D. (eds.) Social Theories of Risk, Praeger: Westport CT, pp. 117-152.

Small Times (2005) "Survey of nanotechnology companies and products" (personal communication).

Stephenson, N. (1996) “The Diamond Age”, London, Penguin Group.

Spinardi, G. and Williams, R. (2005) "The governance challenge of breakthrough science and technology" in: Lyall, C. and Tait, J. (eds.) New modes of governance: developing an integrated policy approach to science, technology, risk and the environment, Ashgate: Aldershot 2005, pp.45-66.

Sweeney, A. E., Seal S.; and Vaidyanathan, P. (2003) "The promises and perils of nanoscience and nanotechnology: Exploring emerging social and ethical issues", Bulletin of Science, Technology and Society, 23(4), pp.236-245.

Tait, J. (2001) "More Faust than Frankenstein: the European Debate about Risk Regulation for Genetically Modified Crops", Journal of Risk Research, 4(2), pp. 175-189.

Tait, J. and Williams, R. (1999) "Policy Approaches to Research and Development: Foresight, Framework and Competitiveness", Science and Public Policy, 26(2), pp. 101-112.

Tegart, G. et al. (2001) "Nanotechnology: The technology for the 21st Century", APEC, Center for Technology Foresight, Bangkok, Thailand.

Tversky, A. and Kahneman, D. (1981) "The Framing of Decisions and the Psychology of Choice," Science, 211, 453-458.

UNIDO (2005) "North-South Dialogue on Nanotechnology: Challenges and Opportunities", United Nations Industrial Development Organisation, International Centre for Science and High Technology: Trieste, Italy.

Van Asselt, M.B.A. (2000) "Perspectives on Uncertainty and Risk", Springer, former Kluwer: Dordrecht and Boston.

Van der Sluijs, J.P., Risbey, J.S., Kloprogge, P., Ravetz, J.R., Funtowicz, S.O., Corral Quintana, S., Guimaraes Pereira, A., De Marchi, B., Petersen, A.C., Janssen, P.H.M., Hoppe, R. and Huijs, S.W.F. (2003) "RIVM/MNP Guidance for Uncertainty Assessment and Communication", Report No. NWS-E-2003-163, Copernicus Institute for Sustainable Development and Innovation and Netherlands Environmental Assessment Agency: Utrecht and Bilthoven.

Viscusi, W.K. (1994) “Risk-Risk Analysis,” Journal of Risk and Uncertainty, 8, pp. 5-18.

Warheit, D. B., Laurence, B. R., Reed, K. L., Roach, D. H., Reynolds, G. A. M. and Webb T. R. (2004) "Comparative Pulmonary Toxicity Assessment of Single-wall Carbon Nanotubes in Rats", Toxicological Sciences, 77(1), pp. 117-125.

(http://toxsci.oxfordjournals.org/cgi/content/abstract/77/1/117)

Webler, T., Levine, D., Rakel, H., and Renn, O. (1991) "The Group Delphi: A Novel Attempt at Reducing Uncertainty," Technological Forecasting and Social Change, 39, pp. 253-263. 
Weil, V. (2003) "Zeroing in on Ethical Issues in Nanotechnology", Proc. of the IEEE, 91, 1976-1979.

Wiener, J.B. (1998) "Managing the latrogenic Risks of Risk Management," Risk: Health, Safety \& Environment, 9, pp. 39-83.

Wildavsky, A., (1990) "No Risk is the Highest Risk of All," in: Glickman, T.S. and Gough, M. (eds.), Readings in Risk, Resources for the Future: Washington, D.C., pp. 120-127.

Williams R. (2005) "Compressed Foresight and Narrative Bias: Pitfalls in Assessing High Technology Futures", Innogen working paper No. 39, under consideration for/accepted by Science as Culture.

Williams, R. and Russell, S. (2002) "Concepts, spaces and tools for action? Exploring the policy potential of the social shaping perspective" in: Sørensen, K. H. and Williams, R. Shaping technology guiding policy: concepts spaces and tools, Elgar: Cheltenham, pp. 133-154.

Wilsdon, J. (ed.) (2001) "Digital Futures: living in a networked world", Earthscan: London.

Winner, L. (1977) "Autonomous Technology. Technics-out-of-control as a theme in political thought", MIT Press: Cambridge MA.

Wolfson, J. R. (2003) "Social and Ethical Issues in Nanotechnology: Lessons from Biotechnology and Other High Technologies" Biotechnology Law Report 22(4), pp. 376-396.

Wynne, B. (1984) "Public Perceptions of Risk", in: Aurrey, J. (ed.), The Urban Transportation of Irradiated Fuel (Mcmillan: London), pp. 246-259

Zhang, Z., Kleinstreuer, C., Donohue, J.F., and Kim C.S. (2005) "Comparison of micro- and nano-size particle deposition in a human upper airway model", Journal of Aerosol Science, 36(2), pp. 211233. 


\section{List of Figures and Tables}

Figure 1. Timeline for beginning of industrial prototyping and nanotechnology commercialization: Four overlapping generations of products

Figure 2. Steps in IRGC risk assessment and management framework for nanotechnology (NT); NS denotes nanostructures.

Figure 3: Strategies as a function of the generation of nanoproducts: application to Frame 1 and Frame 2 .

Figure 4. Environmental, health and safety (EHS) research and regulatory for nanomaterials (Frame 1): key physico-biological processes and decision steps during the life-cycle of nanomaterials released either in the environment or at the working place (modified from Roco (2005b))

Figure 5. Risk governance for active nanostructures and nanosystems (Frame 2): key decision processes in the open loop approach (modified from Roco (2005b))

Figure 6. Acceptable, tolerable, intolerable and undefined risks relative to benefits (Traffic Light Model, a stakeholder perspective)

Figure 7. The risk management escalator and stakeholder involvement (from simple via complex and uncertain to ambiguous phenomena) with reference to nanotechnology

Figure 8: Addressing people's needs and concerns through the stakeholder perspectives: knowledge, industrial, civil, government and global. The role of IRGC is noted in both nanotechnology governance and bridging stakeholders.

Table 1. Risk characteristics and their implications for risk management with reference to nanotechnology.....

Table 2. Key research needs for the two nanotechnology risk frames.

Table 3. Recommendations to stakeholders. 